\title{
MORAL HAZARD AND ECONOMIES OF SCOPE IN PHYSICIAN OWNERSHIP OF COMPLEMENTARY MEDICAL SERVICES
}

\author{
Brian K. Chen \\ Paul J. Gertler \\ Chuh-Yuh Yang \\ Working Paper 19622 \\ http://www.nber.org/papers/w19622 \\ NATIONAL BUREAU OF ECONOMIC RESEARCH \\ 1050 Massachusetts Avenue \\ Cambridge, MA 02138 \\ November 2013
}

The authors have no material or financial interests in the results reported in this paper. The views expressed herein are those of the authors and do not necessarily reflect the views of the National Bureau of Economic Research.

NBER working papers are circulated for discussion and comment purposes. They have not been peerreviewed or been subject to the review by the NBER Board of Directors that accompanies official NBER publications.

(C) 2013 by Brian K. Chen, Paul J. Gertler, and Chuh-Yuh Yang. All rights reserved. Short sections of text, not to exceed two paragraphs, may be quoted without explicit permission provided that full credit, including $\odot$ notice, is given to the source. 
Moral Hazard and Economies of Scope in Physician Ownership of Complementary Medical

Services

Brian K. Chen, Paul J. Gertler, and Chuh-Yuh Yang

NBER Working Paper No. 19622

November 2013

JEL No. I11,I12,K23,L22

\begin{abstract}
When physicians own complementary medical service facilities such as clinical laboratories and imaging centers, they gain financially by referring patients to these service entities. This situation creates an incentive for the physician to exploit the consumers' trust by recommending more services than they would demand under full information. This moral hazard cost, however, may be offset by gains in economies of scope if the complementary services are integrated into the physician's practice. We assess the extent of moral hazard and economies of scope using data from Taiwan, which introduced a "separating" policy, similar to the Stark Law in the US, that restricts physician ownership of pharmacies unless they are fully integrated into the physician's practice. We find that physicians who own pharmacies prescribe $7.6 \%$ more drugs than those who do not own pharmacies. Overall, we find no evidence of economies of scope from integration in the treatment of patients with acute respiratory infections, diabetes, or hypertension. Overall the separating policy was ineffective at controlling drug costs as a large number of physicians choose to integrate pharmacies into their practices in order to become exempt from the policy.
\end{abstract}

Brian K. Chen

University of South Carolina

bchen@mailbox.sc.edu

Paul J. Gertler

Haas School of Business

University of California, Berkeley

Berkeley, CA 94720

and NBER

gertler@haas.berkeley.edu
Chuh-Yuh Yang

Kaohsiung Medical University

Kaohsiung, Taiwan

chunyuh@kmu.edu.tw 


\section{Introduction}

Consumers often turn to experts for advice when they have difficulty discerning the extent to which goods and services meet their needs such as in cases of automotive and appliance repair, engineering services, financial services, and medical care. These experts not only give advice but also sell goods and services to consumers based on that advice. This situation creates an incentive for the expert to exploit consumers' trust and recommend more services than they would demand under full information (Taylor 1995 and Wolinsky 1993). This moral hazard cost, however, maybe offset by gains in economies of scope from the diagnostician also providing the services (Afendulis and Kessler 2007).

This moral hazard inherent in such "credence" goods is present in physician ownership of complementary medical service facilities such as clinical laboratories, imaging centers (i.e., X-rays, CAT scans and MRIs), pharmacies and physical therapy centers. Physicians gain financially by referring patients to a complementary service entity in which the physician has a financial interest. Patients, who rely on physicians for medical advice, have little incentive to reject prescribed procedures especially when insurance covers most of the cost. Because patients have imperfect information on the scope of the problem, diagnosticians have incentive to recommend procedures that are profitable regardless of their cost or appropriateness.

To combat these moral hazard or "self referral" abuses, Congress passed the Stark Law in 1989, which prohibits physician referrals of Medicare and Medicaid patients to complementary care facilities in which the physician or members of the physician's group have a financial interest. ${ }^{1}$ The Law has a "safe harbor" exception that permits physicians to escape prohibition if the self-referral is for services provided within physician offices by a "bona fide employee." In other words, the Law draws a distinction between permissible referrals made within an integrated firm and impermissible referrals made to outside entities. Presumably, the exception for integrated organizations is based on potential economies of scope from the joint production of physician and complementary medical

\footnotetext{
${ }^{1}$ The Stark Law prohibits clinical laboratory, physical and occupational therapy, radiology, radiation therapy, medical equipment and supplies, nutrients, prosthetics, home health, prescription drugs, and hospital services.

${ }^{2}$ See Medicare Part B Imaging Services: Rapid Growth and Shift to Physician Offices Indicate Need for CMS to Consider Additional Management Practices, GAO-08-452, June 2008. See also "MedPAC Seeks to Further Stop InOffice Imaging Incentives," HealthImaging.com, June 21, 2010.

${ }^{3}$ See Medicare: Trends in Fees, Utilization, Expenditures for Imaging Services before and after Implementation of
} 
services. Indeed, economies of scope may arise from better coordination of care and thereby improve patient outcomes (Afendulis and Kessler, 2007).

However, the safe harbor exception also allows physicians to circumvent the intent of the Stark law by integrating complementary services directly into their practices. In fact, there has been massive integration of such services into physician groups since the enactment of the Stark Law (Tynan et al., 2008, United States Government Accountability Office, 2008). For instance, over the last two decades $27 \%$ of physician groups expanded inoffice imaging services. ${ }^{2}$ And Medicare spending for imaging services increased on average $13 \%$ per year, with over two-thirds of the spending occurring in physician office settings. ${ }^{3}$

Policy makers are keenly aware of the problems with the exemption. The Medicare Patient Advisory Commission recently proposed extensive changes to limit the exemption. And the Center for Medicare and Medicaid Services recommended that physicians who make self-referrals must disclose their financial interests to patients in a June, 2010 Report to Congress under the Patient Protection and Affordable Care Act of 2010.

In this paper, we use data from Taiwan to estimate the moral hazard costs and gains from economies of scope associated with physician ownership of pharmacies. For identification, we exploit a policy prohibiting physicians from owning pharmacies and dispensing drugs that was phased in geographically over time. The "separating" policy included a safe harbor exemption for physician groups that have an onsite pharmacy with a licensed pharmacist integrated into their practice, which is identical to the safe harbor provision in the Stark Law.

Our analysis is made possible by a novel data set the links patient claims over time to medical care providers for the universe of patients and providers. Taiwan is a country with OECD level income and health status indicators. It also has a sophisticated health care delivery system with a universal single-payer health insurance system similar to Canada (Lu and Hsiao, 2003). The single payer insurance plan maintains individual claims data that can be linked over time and to providers.

\footnotetext{
${ }^{2}$ See Medicare Part B Imaging Services: Rapid Growth and Shift to Physician Offices Indicate Need for CMS to Consider Additional Management Practices, GAO-08-452, June 2008. See also "MedPAC Seeks to Further Stop InOffice Imaging Incentives,” HealthImaging.com, June 21, 2010.

${ }^{3}$ See Medicare: Trends in Fees, Utilization, Expenditures for Imaging Services before and after Implementation of the Deficit Reduction Act of 2005, GAO-08-1102R, September 26, 2008.
} 
We estimate that the separating policy significantly reduced drug expenditures among physicians that did not have an onsite pharmacy. However, the effect of the policy on reducing the total costs of care was substantially smaller for a number of reasons. First, physicians responded by increasing the overprovision of self-referred diagnostic services not covered by the policy. Second, more than half of the physician groups (clinics) already had an onsite pharmacy prior to the policy and therefore were exempt. Third, close to $40 \%$ of the clinics that did not have an onsite pharmacy prior to the policy integrated onsite pharmacies into their practices after the implementation of the policy.

Our results show that policymakers are correct to be concerned about physicians referring patients to an entity in which they have a financial interest. We find evidence of significant moral hazard as owning a pharmacy increased physician drug prescriptions by 7.6\%. In contrast, we find no evidence to support any gains due to economies of scope from the integration of pharmacies into physician offices. First, integration failed to create efficiency savings; indeed, it generated the opposite result, as moral hazard effects dominate. Second, integration did not improve adherence to medication prescriptions for patients with the chronic diseases diabetes and hypertension. Finally, we find no effect of integration on preventable adverse medical events in the treatment of patients with acute respiratory infections, diabetes, and hypertension. This the safe harbor exception severely limited the policy's effectiveness as physicians exploited the loophole to be able to continue to engage in profitable self-referrals without any off setting gains from economies of scope.

Our work makes several contributions to the understanding of health care markets. First, we among the first to provide empirical evidence of a causal role of self-referral incentives in the overprovision of complementary medical care services. ${ }^{4}$ Second, our work is among the first to empirically examine policies such as the Stark Law that regulate selfreferrals abuse. Third, our work is first to examine the effect of policies such as the Stark Law on the organizational structure of the industry.

\footnotetext{
${ }^{4}$ Most of the work reports cross-sectional correlations that are consistent with the overtreatment hypothesis. For example see Childs and Hunter (1972), Strasser et al (1987), Hillman et al (1990, 1995, 1992), Aronovitz (1994), Mitchell and Sass (1995), Gazelle et al (2007), Mitchell (2005) and Mitchell (2008). One important exception is Iizuka (2007) who shows that physicians who dispense their own drugs in Japan take a drug's markup into account in prescription decisions.
} 
Our work also contributes to the more general literature on moral hazard concerns that arise in credence good markets. Chevalier and Ellison (1997) find that mutual fund managers often try to increase the inflow of funds against the interests of their customers. Hubbard $(1998,2002)$ investigates the California vehicle emissions inspection market where inspectors also provide repairs to help vehicles pass. Levitt and Syverson (2008) show that homes owned by real estate agents sell for higher prices than comparable homes owned by non-agents. Gruber and Owings (1996) document a negative relationship between birth rate and Cesarean section delivery as evidence of physician-induced demand for costly procedures. Iizuka (2007) shows that physicians who dispense their own drugs in Japan take a drug's markup into account in prescription decisions. Finally, Afendulis and Kessler (2007) examine the tradeoffs between moral hazard and economies of scope in the joint production of diagnosis and treatment of cardiac conditions.

\section{Conceptual Framework}

We model the prohibition against self-referrals as a fee reduction in complementary services that the physician prescribes (recommends) to patients. Suppose physicians prescribe two types of complementary services: (1) services that are subject to the prohibition such as drugs and (2) services that are not subject to the prohibition such as imaging. Physician income from complementary services can be represented simply as $Y=N\left(\pi_{1} s_{1}\left(w_{1}\right)+\pi_{2} s_{2}\left(w_{2}\right)\right)$ where $N$ is the number of patients she sees, $\pi_{i}$ is the profit margins for service $i$, and $s_{i}$ is the quantity of service $i$ provided, which depend on $w_{i}$ - the amount of overtreatment. If the physician provides the clinically appropriate level of care, then the level of overtreatment is zero.

Physicians gain income from over-treating patients, but pay a cost in terms of disutility. Before the prohibition, the equilibrium amount of overtreatment equates the marginal income from overtreatment of each service to the marginal disutility from total overtreatment. The prohibition reduces the profit margin for drugs, $\pi_{1}$, to zero. In this case, the physician prescribes only the amount of drugs needed and overprovision of drugs is zero. However, the physician increases over-provision of non-prohibited services from which she still has a positive return. 
Physicians with an onsite pharmacy are de jure exempt from the prohibition and there is no impact of the policy on their overprovision of drugs. One option for those that do not have onsite pharmacy is for them to legally circumvent the prohibition policy by integrating a pharmacy into their practice. However, having a pharmacy requires paying the fixed costs that include salary, space, equipment, and training.

The physician integrates a pharmacy into her medical practice if the profits from having an onsite pharmacy are larger than not having one. The net income from integration is $Y^{p h}=N\left(\pi_{1} s_{1}\left(w_{1}^{*}\right)+\pi_{2} s_{2}\left(w_{2}^{*}\right)\right)-F$, where $F$ is the fixed cost of having a pharmacy and $w_{i}^{*}$ is the optimal overprovision. The income generated without a pharmacy is $Y^{n o}=N \pi_{2} s_{2}\left(w_{2}^{\prime}\right)$ where $w_{i}^{\prime}$ is the optimal overprovision under the prohibition. A physician, then, hires a pharmacy if $Y^{P h}-Y^{n o}>0$, which translates into

$$
N>\frac{\mathrm{F}}{\pi_{1} \mathrm{~s}_{1}\left(\mathrm{w}_{1}^{*}\right)+\pi_{2} \mathrm{~s}_{2}\left(\mathrm{w}_{2}^{*}\right)-\pi_{2} \mathrm{~s}_{2}\left(\mathrm{w}_{2}^{\prime}\right)} .
$$

The physician will integrate if the number of patients is larger than the fixed cost divided by the per-patient marginal profit from having an onsite pharmacy. The larger the fixed costs and the lower the return to overprovision, the greater the number of patients required for integration to be profitable. In other words, there needs to be sufficient scale to be able to cover the fixed costs.

The framework provides us with a number of empirically testable predictions. First, the prohibition policy will reduce drug prescriptions by physicians in clinics that do not have a pharmacy on site. Second, moral hazard from self-referral incentives is the difference in drug expenditures for patients who are treated by physicians with and without an onsite pharmacy. Third, the policy will increase the over-provision of other nonprohibited complementary services meaning that any efficiency gains from reducing unnecessary drug prescriptions will be at least partially offset by increases in other services. Third, the exemption to the prohibition gives clinics an incentive to integrate pharmacies into their practice to circumvent the prohibition if they have sufficient patient volume to cover the fixed costs. 


\section{Institutional Context}

Taiwan is a country of 23 million people that has an advanced market economy with a per capita GDP of US\$32,200. Taiwan's health indicators are on par with OECD nations: Life expectancy in Taiwan is 72 for men and 78 for women, and infant mortality is 6.14 per 1,000 live births. Taiwan's health care infrastructure is also comparable to those of many OECD countries, with 5.7 hospital beds and 8.7 medical professionals per 1,000 (Lu and Hsiao, 2003). By 2007, total health expenditures represented $6.3 \%$ of Taiwan's GDP, of which $21 \%$ consisted of prescription drug expenditures.

Taiwan's health care system, modeled after Canada, is publicly financed with patients free to choose among a mixture of private and public medical care providers. Taiwan's National Health Insurance has achieved universal enrollment for a comprehensive package of medical services. Virtually all health care providers are under contract with the National Health Insurance Bureau (NHIB), which pays physicians fee-for-service for consultations, diagnostic tests performed in the office, and writing drug prescriptions (Cheng, 2003).

Prior to 1997, physicians were also allowed to dispense drugs directly out of their offices (Wagstaff, 2007). NHIB paid physicians for dispensing drugs based on a set of fixed formulary fees. Physicians, however, were able to procure the drugs directly from manufacturers at a much lower cost than the NHI formulary prices (Eggleston, 2009). As a result, physicians reaped handsome profits from the sale of drugs.

In 1997, facing rapidly rising prescription drug expenditures, Taiwan instituted an anti-self-referrals policy called the "separating" policy, designed to disentangle physicians' diagnosis and treatment decisions from the financial incentive to prescribe drugs (Chou et al., 2003). The "separating" policy prohibited clinics from dispensing drugs directly by physicians from their offices and physicians from owning offsite pharmacies.

There were a number of exceptions. First, like the Stark Law's safe harbor exception, physician clinics that have an onsite pharmacy with a licensed pharmacist, dedicated space with adequate storage, refrigeration and record keeping were allowed to continue to dispense drugs. Second, clinics without an onsite pharmacy were allowed to continue to dispense drugs to children and the elderly for acute medical conditions for which quick dispensing of drugs was deemed important. 
The separating policy was rolled out across villages over the course of several years, beginning in March 1997. Before enforcing the policy in a village, the NHIB had to ascertain that there were sufficient numbers of independent pharmacies where patients could fill their prescriptions. Villages became subject to the policy as soon as the NHIB determined there was at least 1 independent pharmacy for every 500 residents. There was a sharp increase in pharmacists following the implementation of the policy. Between 1997 and 2001 the number of licensed pharmacists grew from 23,892 t over 40,000, and pharmacist monthly salaries jumped dramatically from an average of US\$ 625 to US\$ 1870.

There was concern that physicians tried to get around the separating policy through "gateway pharmacies," which are legally independent pharmacies registered in the name of the pharmacist but in reality owned by clinic physicians. Although the true status of independent pharmacies is unobservable, Lee (2007) defined gateway pharmacies as those for whom $70 \%$ of their prescriptions came from a single physician group. He estimated that only $3.6 \%$ of clinics used gateway pharmacies in 2000 , the end of our study period.

\section{Data}

Our data is a $0.2 \%$ random sample of all ambulatory care claims from 1997 through $2000 .{ }^{5}$ While the separating policy was implemented at the village level, the claims data provide geographic identification at the township level; each township includes multiple villages. We drop data from townships with mixed implementation dates, approximately $25 \%$ of the sample. While Townships are more aggregate than villages they are substantially smaller than municipalities. Taiwan has 24 municipalities and 194 Townships.

The unit of observation is the outpatient visit. Available information in the dataset includes use of and expenditures for physician and complementary medical services associated with those office visits, regardless of where those services were provided.In Table 1 we provide baseline descriptive statistics disaggregated by a clinic's integration status at baseline - i.e. whether they had a pharmacy inside the clinic. At baseline, prior to the separating policy, 35\% of clinics had an onsite pharmacy (Table 1, Panel B). Consistent

\footnotetext{
${ }^{5}$ We limit our study to the period ending on December 31, 2000 as the separating policy was implemented in most of Taiwan by the end of 2000 and the NHIB changed physician payment from fee for service to Global Budgets in 2001.
} 
with our conceptual framework, the integrated clinics were substantially larger than the non-integrated clinics in terms scale (visits and revenues). While integrated clinics are larger than non-integrated clinics, there are no real differences in the types of patients that they attract or in they way in which they treat those patients.

\section{Policy Impact}

In this section we estimate the reduced-form impact of the separating policy on clinics that did not have a pharmacy onsite at baseline. The effect is reduced form in the sense that it is an average of the effects for clinics subject to the policy at baseline regardless of their decision to integrate in reaction to the policy.

\subsection{Event History Analysis}

Figures 1 and 2 plot the share of visits that receive drug prescriptions and the average drug expenditure per visit conditional on positive expenditures over time for 3 groups: (1) clinics that never had an onsite pharmacy (never) and therefore were subject to the separating policy, (2) those that did not have an onsite pharmacy prior to the policy but added one post policy (switchers) and thus became exempt form the policy, and (3) those that had an onsite pharmacy prior to the implementation of the policy (always) and therefore were always exempt from the policy. The horizontal axis is centered at time zero, which is the month in which the separating policy became effective in the township in which the clinic is located. Observations to the right of zero refer to months post implementation, and observations to the left refer to months prior to implementation.

Prior to the implementation of the separating policy, the levels and trends of drug prescriptions are similar for all 3 types of clinics. However, after implementation, drug prescriptions fell in the never clinics who were subject to the policy. On the other hand, drug prescriptions in the always and switcher clinics who were exempt from the policy continued on trend after the implementation of the policy.

\subsection{Identification Strategy}

We use a difference-in-differences approach that compares the change in outcomes in the treatment group to the change in outcomes in a comparison group. The change in the 
comparison group is an estimate of the true counterfactual - that is, what would have happened to the treatment group if there were no intervention. The strategy controls for time-invariant characteristics at the physician level as well as time-varying factors common to both comparison and treatment physicians at the local municipality level, and for heterogeneity in patient demographic and epidemiological case-mix.

Our comparison group is the set of clinics that had onsite pharmacies at baseline and therefore were not subject to the separating policy. The advantage of this comparison group is that they are located in the same municipalities as the treatment group. This allows us to control for time-varying factors that may have been introduced contemporaneously at the municipality level with the implementation of the policy, but allows time-varying shocks to have different impacts across municipalities. Examples include new local health policies, differential economic growth, and differing changes in the local epidemiological environment.

We estimate the following specification:

$$
y_{i j k m t}=\alpha_{j}+\gamma_{m t}+\sum_{l} \delta_{l} x_{i t}+\beta\left(1-I_{j, p r e}\right) T_{k t}+\varepsilon_{i j k m t}
$$

where

- $y_{i j k m t}$ is the dependent variable for patient $i$ who is treated by physician $j$ living in township $k$ and municipality $m$ in period $t$;

- $\quad \alpha_{j}$ is a fixed effect for physician $j$;

- $\gamma_{m t}$ is a fixed effect for municipality $m$ in time period $t$;

- $x_{i t}$ is a vector of individual patient characteristics including age, sex and 65 indicators of the patient's primary illness diagnosis;

- $I_{j, p r e}=1$ if clinic $j$ had an onsite pharmacy prior to the implementation of the policy;

- $T_{k t}=1$ if the separating policy is in force in township $k$ in period $t$; and

- $\varepsilon_{i j k m t}$ is a zero mean random error.

The coefficient $\beta$ is the difference-in-difference estimate of the impact of the policy on drug expenditures and diagnostic expenditures. The physician fixed-effects control for unobserved heterogeneity between physicians. The 65-illness indicators combined with patient age and sex control for heterogeneity in patient case-mix. And the municipality specific time fixed-effects control for factors that change over time but are common to both 
treatment and comparison groups within each municipality. The standard errors are clustered at the township level.

\section{3. $\quad$ Results}

The results, presented in Panel A of Table 2, are consistent with our theoretical predictions. The separating policy reduced the likelihood of prescription by 1.4 percentage points and drug expenditures conditional on a prescription by $3.8 \%$. These translate into a reduction in total drugs expenditures of 5.2\% among clinics that did not have an onsite pharmacy at baseline. ${ }^{6}$ Physicians did compensate by slightly increasing the share of patients that had diagnostic tests but there was no effect on physician services. Overall, the policy reduced total costs (drug plus diagnostic plus physician services) by $1.3 \%$ in clinics not integrated at baseline. However, the policy was binding only for clinics that did had an onsite pharmacy, which at baseline treated $40 \%$ of patients. Hence, the overall impact on total drug expenditures was only $1.7 \%$ and on total expenditures was a reduction of $0.5 \%$.

Our results are substantially smaller than those of Chou et al (2003) who report a $16 \%$ reduction in the probability of prescription and a $12 \%$ fall in drug costs conditional on a prescription associated with the initial implementation of the separating policy. They compared the average change in drug expenditures in two municipalities nine months after the policy was implemented compared to the average change in two other cities that had not yet implemented. Some of the reasons for these differences could due to: (1) we examine the impact of the policy nationwide in all 24 municipalities and for a substantially longer period (3 years); (2) the short recall period in the Chou et al analysis may not have long enough to fully capture the extent to which clinics integrated pharmacies onsite to circumvent the policy, which would tend to lower the estimates; (3) we employ a visit level analysis that additionally controls for physician fixed effects, patient and illness characteristics, and time-varying factors at the municipality level; and (4) we also confirm the validity of our comparison groups using a number of robustness and specification tests.

\footnotetext{
${ }^{6}$ We calculate $\% \Delta$ in expenditures as follows. Note that $E(E x p)=E(E x p \mid E x p>0) * \operatorname{Prob}(\operatorname{Exp}>0)$. Totally differentiating and rearranging terms gives us $(\Delta E x p / E x p) * 100=(\Delta E(E x p \mid E x p>0) / E(E x p \mid E x p>0)+$ $\Delta \operatorname{Prob}(\operatorname{Exp}>0) / \operatorname{Prob}(\operatorname{Exp}>0)) * 100$. The terms $\Delta E(\operatorname{Exp} \mid \operatorname{Exp}>0) / E(\operatorname{Exp} \mid \operatorname{Exp}>0)$ and $\Delta \operatorname{Prob}(\operatorname{Exp}>$ $0)$ are estimated coefficients and $\operatorname{Prob}(\operatorname{Exp}>0)$ is estimated as the baseline mean for the clinics that did not integrate from Table 1.
} 


\subsection{Control Group Validity}

\subsubsection{Baseline Balance of Treatment and Comparison Groups}

We first show that the treatment and comparison sample is balanced in 1997 prior to the implementation of the policy. This rules out Ashefelter dip type explanations for treatment effects in the difference in difference estimates. Panel A in Table 1 compares the means of patient characteristics and treatment patterns of the treatment clinics (Not Integrated) and comparison clinics (Integrated). Both treatment and comparison clinics attracted the same type of patients and provided those patterns with the same type of care in terms of drug prescriptions and diagnostic tests. There are no statistically significant differences in the means of 12 out of the 13 patient level variables in Table 1 . Specifically, we find no differences in patient sex and or in medical reason for the visit. Slightly over $40 \%$ of their office visits to both types of clinics are for a respiratory infection. Physicians in both types of clinics preform diagnostics test on about 3\% of patients and spent about the same amount on those tests. Physicians in both types of clinics also prescribed medications to almost all patients, prescribed identical classes of medications (primarily of antacids, anti-inflammatory agents, antihistamines, and other palliative medications associated with the common cold or upper respiratory infections), and prescribed the same amount in terms of expenditures on drugs. The one difference in that slightly younger patients seem to visit integrated clinics. ${ }^{7}$

\subsubsection{Pre-intervention Trends}

The key assumption underlying the causal interpretation in our difference in differences model is that the change in the comparison group is an unbiased estimate of the counterfactual - i.e. what would have been the change in the treatment group without the separating policy. While we cannot directly test this assumption, we did employ the Heckman-Hotz test that asks whether the pre-intervention trends of the treatment group are different from those of the comparison group. If the pre-intervention trends are not different, there would be no reason to assume that they would be different in the post period without the intervention.

\footnotetext{
${ }^{7}$ Recall that we explicitly control for patient age along with gender and illness diagnosis in the models.
} 
We implement the test by dropping all post-policy observations from our sample, and running the following model:

$$
y_{i j k m t}=\alpha_{j}+\gamma_{m t}+\sum_{l} \delta_{l} x_{i t}+\sum_{m} \lambda_{m}\left(1-I_{j, p r e}\right) l_{m} \operatorname{Trend}_{t}+\varepsilon_{i j k m t}
$$

where $l_{m}=1$ if the clinic is located in municipality $m$, Trend $t$ is a continuous time variable indicating quarter, and all other variables are as defined for equation (2).

The coefficients of interest are the $\lambda_{m}$ 's on the interaction terms of the municipality dummies, future treatment dummies and the time trend. Note that we test if the preintervention trends are equal for each municipality separately and jointly. If these are jointly zero, then we reject the hypothesis that the pre-intervention trends are different for the treatment and comparison groups.

We estimate equation (3) for each of the dependent variables. Almost all of the $\lambda_{m}$ 's (84 out 90) are not significantly different that zero and the F-statistics for the hypothesis that all of the coefficient interaction terms are jointly for each outcome zero cannot be rejected at conventional significance levels for each of the five dependent variables (Appendix Table A1).

\subsection{Robustness Tests}

\subsubsection{Alternative Identification Strategy}

Another source of variation that can be used to identify causal impacts comes from the fact that the policy was phased in geographically over time. In this case the treatment group consists of clinics located in the municipalities that were early adopters of the policy and the comparison group consist of those located in late adopter counties. In this case the treatment group consists of clinics located in the townships that were early adopters of the policy and the comparison group consist of those located in late adopter townships.

However, this strategy has two limitations. First, it can only controls for time varying shocks that are common across all treatment and comparison areas, but not for time varying shocks that idiosyncratically vary across townships. This approach also has a smaller sample as it uses only the clinics that did not have an onsite pharmacy at baseline.

The specification is identical to equation (2), except that the time fixed-effects do not varying by municipality. We find that point estimates, presented in Table 2 Panel B, are 
very close to the main regression results in Panel A and most are statistically significant. However, some of the estimates are somewhat less precise due to substantially smaller sample sizes and more limited variation for identification.

\subsubsection{Placebo Test}

The fact that there are no differences in the pre-intervention trends is consistent with the identifying assumptions that the change in the control group is a consistent estimate of the counterfactual. However, we still cannot completely rule out that the remote possibility that post trends may have diverged within municipalities due to some unobservable post policy time-varying factors. We use a placebo test to rule out this possibility. Specifically, we estimate the reduced form specified in equation (2) on the sample of visits to clinics by patients who are exempt from the separating policy i.e. the young and the elderly. Since they are exempt, the introduction of the separating policy should have no effect on drug and diagnostic expenditures for these patients. The results are presented in Panel $\mathrm{C}$ of Table 2 and show no effect of the separating policy.

\subsubsection{Patient Sorting}

An alternative explanation of the results could be patient sorting in response to the policy, i.e. patients who had strong preferences for drugs or the convenience of filling their prescriptions onsite switched to control facilities as a result of the policy. To address this possibility, we examined patient clinic switching behavior using a panel data set of 200,000 individuals. Of those, 155,343 sought care at a clinic at least once between January 1, 1997 and December 31, 2000. On average, patients sought care six times per year. Of those that patronized clinics without a pharmacy at baseline, only $347(0.2 \%)$ switched to visit a different clinic with a pharmacy after the policy was implemented in their township.

\section{Moral Hazard}

The moral hazard effect is the extra drug expenditures resulting from the incentive to prescribe more drugs from physician ownership of pharmacies. The moral hazard effect is simply the difference in drug expenditures with and without pharmacy ownership. We identify this by estimating the effect of the separating on physician treatment decisions 
with and without onsite pharmacies. This requires us to estimate the effect of the policy on physician behavior explicitly taking into account the decision to integrate pharmacies.

\subsection{Integration}

A substantial number of clinics not integrated at baseline (38\%) chose to integrate after the policy was implemented and the that integrated on average had $68 \%$ more patient visits than those that did not. Figure 3 displays integration overtime separately for clinics in different parts of the baseline distribution of patient volume. The probability of integration is effectively zero up until the separating policy becomes effective and then increases dramatically shortly thereafter with substantially larger increases for the medium- and large-volume clinics.

These graphical results are confirmed in a difference-in-difference analysis of the impact of the policy on the integration. We estimate a clinic level version of equation (2) for integration using the sample of clinics that were not integrated at baseline. Model (1) confirms that $66 \%$ of clinics choice to integrate. Model (2) adds interactions of treatment with the baseline quartile of the distribution of number of visits. The results show that clinics that had larger volumes of patients at baseline were more likely to integrate.

\subsection{Identification Strategy}

We employ a triple differences strategy that assumes that the decision to integrate was based on fixed characteristics. Specifically, we compare the difference-in-difference estimate of the impact of the policy on clinics that did not integrate to the difference-indifference estimate of the impact on clinics that did integrate. The first double difference compares the change in outcomes of those that did not integrate to those that were integrated at baseline and the second double difference compares the change in those that did integrate to those that were integrated at baseline.

The assumption that the decision to integrate is based on time-invariant characteristics is consistent with the fact the almost all clinics that integrated did so immediately after the policy is implemented in their township (Figure 3). Moreover, while patient volume is correlated with the decision to integrate (Table 3, Panel B) as predicted 
by theory, there are no baseline differences in the types of patients treated or in the treatment patterns between the types of clinics (Table 3, Panel A).

We adjust the specification in (2) to allow the effect of the separating policy to the clinic's integration status and integration interacted with treatment:

$$
y_{i j k m t}=\alpha_{j}+\gamma_{m t}+\sum_{l} \delta_{l} x_{i t}+\beta\left(1-I_{j, p r e}\right) T_{k t}+\phi\left(1-I_{j, p r e}\right) T_{k t} I_{j t}+\varepsilon_{i j k m t}
$$

where $I_{j t}=1$ if clinic $j$ is integrated in period t and the rest are defined as in equation (2).

The moral hazard effect is calculated from $\beta$, which is the effect of the policy on clinics that did not integrate. This is effect of removing the incentive to overprescribe drugs by eliminating physician profits from drug sales through the ownership of pharmacies. The effect of the policy on clinics that integrated is $\beta+\phi$, which should be zero.

\subsection{Results}

The results are presented in panel A of Table 5. We find that the separating policy reduced the probability that a physician working in a non-integrated clinic gave a drug prescription by 2.1 percentage points and average drug expenditures conditional on a prescription by $4.9 \%$. Hence, the separating policy reduced drug expenditure fell by $7.1 \%$ for this group. ${ }^{8}$ We also find that these physicians slightly increased diagnostic tests. Overall, the separating policy reduced total outpatient expenditures by $1.8 \%$. As expected, however, the separating policy had no effect on physicians who worked in clinics that integrated and, as a result, were exempt from the separating policy -- Row (a) + (b).

Our results imply that the moral hazard cost of physicians owning pharmacies is non-trivial. At baseline, mean drugs expenditures at baseline were NT\$88.91 for the group of clinics that did not integrate. A 7.1\% reduction caused by the separating policy that eliminated the incentives from physician ownership means that costs were reduced by NT\$6.31 to NT\$82.67, which can be interpreted as the "appropriate" amount of drugs for the treatment of the patient. Moral hazard increased expenditures by NT $\$ 6.01$ or $7.6 \%$.

\footnotetext{
${ }^{8}$ We calculate $\% \Delta$ in expenditures as follows. Note that $E(E x p)=E(\operatorname{Exp} \mid \operatorname{Exp}>0) \operatorname{Prob}(\operatorname{Exp}>0)$. Totally differentiating and rearranging terms gives us $(\Delta \operatorname{Exp} / \operatorname{Exp}) * 100=(\Delta E(E x p \mid \operatorname{Exp}>0) / E(E x p \mid \operatorname{Exp}>0)+$ $\Delta \operatorname{Prob}(\operatorname{Exp}>0) / \operatorname{Prob}(\operatorname{Exp}>0)) * 100$. The terms $\Delta E(\operatorname{Exp} \mid \operatorname{Exp}>0) / E(\operatorname{Exp} \mid \operatorname{Exp}>0)$ and $\Delta \operatorname{Prob}(\operatorname{Exp}>$ $0)$ are estimated coefficients and $\operatorname{Prob}(\operatorname{Exp}>0)$ is estimated as the baseline mean for the clinics that did not integrate from Table 3.
} 


\subsection{Control Group Validity}

\subsubsection{Baseline Balance}

Despite that fact that larger clinics chose to integrate, there was no difference in the types patients nor in the treatment patterns between clinics that chose to integrate and those that did not (Table 3, Panel A). This rules out Ashenfelter dip explanations of the results. Specifically, we find no differences in patient sex and or in medical reason for the visit. Physicians in both types of clinics preform diagnostics test on about 3\% of patients and spent about the same amount on those tests. Physicians in both types of clinics also prescribed medications to almost all patients, prescribed identical classes of medications, and prescribed the same amount in terms of expenditures on drugs. The one difference is that patients who visited integrated clinics were younger and we explicitly control for this in all models.

\subsubsection{Pre-intervention Trends Tests}

The key assumptions underlying the causal interpretation in our triple differences model are that the change in the group integrated at baseline is an unbiased estimate of what would have been the change in the group not integrated at baseline that choose to integrate and an unbiased estimate of the group that choose not to integrate. Again, while we cannot test this directly, we can employ The Heckman-Hotz tests of pre-intervention trends. We have already shown the there is no difference in the pre-intervention trends of the groups that were and were not integrated at baseline. In this section, we test equality of the pre-intervention trends of the groups that were not integrated at baseline that choose to integrate and that choose not to integrate.

We implement the test by dropping all post-policy observations from our sample and estimate the following model for the group of clinics that were not integrated a baseline:

$$
y_{i j k t}=\alpha_{j}+\gamma_{k t}+\sum_{l} \delta_{l} x_{i j k l}+\sum_{k} \lambda_{k} I_{j k} \sum_{t} \operatorname{Trend}_{t}+\varepsilon_{i j k t}
$$

where $I_{j k}$ is a dummy variable indicating whether physician $j$ in municipality $k$ will be in an integrated group in the post period, Trend $_{t}$ is a continuous time variable indicating quarter,

and all variables are as defined for equation (3). The coefficients of interest are the $\lambda_{k}$ 's on the interaction of the municipality dummies, integration dummy and time trend. 
We estimate equation (5) for each of the dependent variables. Almost all of the $\lambda_{k}{ }^{\prime}$ (78 out 80 ) are not significantly different that zero. The hypothesis that all of the coefficient interaction terms are jointly for each outcome zero also cannot be rejected at conventional significance levels for 4 out of the 5 dependent variables (Appendix Table A2).

\subsection{Placebo Test}

We also estimate the triple differences model in equation (4) on the sample of visits to clinics by patients who are exempt from the separating policy i.e. the young and the elderly. Since they are exempt, the introduction of the separating policy should have no effect on drug and diagnostic expenditures for these patients. The results are presented in Panel C of Table 5 and show little or no effect of the separating policy.

\subsection{An Alternative Identification Strategy}

As a robustness test we also estimate the triple differences model by using instrumental variables to control for the possibility that the integration decision was in part in response to time-varying shocks to specific clinics within municipalities. Our instrument is baseline practice volume interacted with the timing of the introduction of the separating policy in the clinic as an instrument for integration. ${ }^{9}$ The instrument is the empirical analogue of the volume variable in the theoretical model interacted with whether the policy is active.

\subsubsection{Instrument Validity}

We have already shown that the instrument is a highly significant predictor of the probability that the clinic integrates. It is also highly correlated with the outcomes of interest. Figures 4 and 5 plot the share of visits receiving a prescription and the average drug expenditures per visit over time separately by four baseline practice volume quartiles. Drug prescriptions rise the most post-policy for the smallest group and do not rise for the largest groups.

One potential concern with this instrument, however, is the larger clinics attract different types of patients and are able to treat those patients with different (better) procedures. However,

\footnotetext{
${ }^{9}$ Specifically, we re-estimate the triple difference model in equation (4) by instrumental variables. We instrument for treatment times pharmacy with $\mathrm{D}_{40}\left(=1\right.$ if the baseline practice volume exceeds 40,000 visits per year) and $\left(1-\mathrm{D}_{40}\right)$ $\times \log$ baseline volume, both interacted with a dummy indicating that the separating policy was active in which the clinic was located.
} 
baseline clinic volume also does not seem to be correlated with the baseline type of patients, types of illnesses treated or provider treatment patterns as there is no difference in these variables between clinics that choose to integrate and those who did not (Table 3 Panel A). Hence it is unlikely that baseline volume is an independent cause of the outcomes of interest.

\subsubsection{Triple Difference Results}

The results are presented in panel B of Table 5. The estimate of moral hazard in row (a) is almost identical to that which we found using the simple triple difference strategy. Specifically, the separating policy reduced the probability that a physician working in a non-integrated clinic gave a patient drug prescription by 2.7 percentage points and reduced average drug expenditures per visit by 4.9 percent. This reduced total drug expenditures by $7.7 \%$. We also find almost identical effects on diagnostic test expenditures as well and overall total expenditures.

In contrast to the triple differences results, we do find that integration, row (a) $+(b)$, increased total expenditures by $2.3 \%$ primarily through increased drug expenditures. One reason may be that clinics without a pharmacy are not able to dispense certain types of drugs and must refer to an independent pharmacy. By integrating an onsite pharmacist into their practices, they are now able to dispense these types of drugs and hence can exploit this fact for further gain.

\section{Economies of Scope}

In this section we examine potential gains from integration resulting from economies of scope that may improve quality of care. There are two possible routes to improved care. First, integration could improve therapy adherence, i.e. patients following drug prescription regimes have lower costs of filling and refilling prescriptions when pharmacies are located in the physician's office and therefore have better adherence to their prescribed medication regimes. Second, integration may improve the coordination of care through better communication between physicians and pharmacists at the prescription phase resulting in improved treatment plans.

\subsection{Therapy Adherence}

We examine medication adherence for two chronic diseases - diabetes and hypertension. Medication adherence is particularly important for both type of patients 
Persistent high levels of blood sugar can have immediate short-term effects that require some form of emergency treatment and blood pressure can spike even after a two-day drug holiday from medication (Ribeiro et al. 2007). High levels of medication adherence are associated with lower hospitalization rates for both types (Sokol et al., 2005).

We measure therapy adherence by the extent to which patients with chronic diseases fill their drug prescriptions on time. The hypothesis is that patients are more likely to fill drug prescriptions if they are able to do so in the clinic at the time of prescription rather than having to fill them later at a pharmacy outside of the clinic. The adherence measure is the share of days per quarter that the patient has medication in her possession, a common measure of adherence in the medical literature (Osterberg and Blascke 2005).

We test for economies of scope in therapy compliance using the triple differences model. If integration improves adherence then the effect of the policy on clinics that did not integrate should be negative and there should be no effect of the policy on clinics that did integrate. We find no effects on therapy adherence for both diabetic and chronically ill hypertensive patients (Table 6).

\subsection{Adverse Events}

We examine adverse events from deficient medical treatment measured by an avoidable ER visit or hospitalization shortly after the outpatient visits to clinic. ${ }^{10} \mathrm{We}$ consider adverse events for three types of prevalent patient diagnoses: acute respiratory infections (ARI), diabetes, and hypertension - the most prevalent chronic diseases in the majority of industrialized economies. These diseases are ambulatory care sensitive conditions for which good primary care and drug adherence can drastically reduce or even eliminate the need for hospitalizations or ER visits. Moreover, any clinically significant interruption in treatment of diabetes and hypertension is likely to manifest as an adverse event in a relatively short time-horizon (Ho et al., 2006, Sokol et al., 2005, Wu et al., 2009). When ARI is not treated, it can manifest itself into more serious problems such as pneumonia that could require hospitalization.

\footnotetext{
${ }^{10}$ These avoidable adverse events are typically caused by deficient medical treatment. See, for example, DiMatteo et al. (2002), Lee et al, (2006), Mojtabai and Olfson (2003), Osterberg and Blaschke (2005), Simpson et al. (2006), and Tabor and Lopez (2004).
} 
For ARI, we examine ER utilization and inpatient admissions within 30 days of the office visit. For diabetic and hypertensive patients, we examine ER utilization and hospitalization rates within 360 days of the visit as medical issues associated with uncontrolled diabetes or hypertension can take time to develop. The results, reported in Table 7, show no significant effects on either adverse event measure for any of the diseases.

\section{Conclusions}

A concern of anyone who consults a doctor, plumber, or auto mechanic is the incentive to give advice that is not in the buyer's best interests. Nowhere is this truer than when physicians have an ownership interest in complementary medical services, and is the reason that led to the Stark Law that prohibits referrals of Medicare and Medicaid patients to complementary care facilities in which the physicians have a financial interest.

In this paper, we investigated a Stark-like policy in Taiwan that prohibited physicians from owning pharmacies and dispensing drugs unless they had an onsite pharmacy. We find that the policy reduced drug expenditures among physicians that did not have an onsite pharmacy. However, the overall effectiveness of the policy in reducing costs was mitigated by increased overprovision of diagnostic services not covered by the policy, and many of clinics that did not have an onsite pharmacy prior to the policy integrated onsite pharmacies into their practices to become exempt from policy. In the end, the policy only applied to less than $40 \%$ of clinics. As a result, the separating policy only reduced aggregate outpatient expenditures by less than 1 percent.

Despite this policymakers are correct to be concerned about physicians referring patients to an entity in which they have a financial interest because of the potential for overtreatment. Our results do show that moral hazard costs of self-referral incentives are significant. Physicians that own pharmacies prescribe $7.6 \%$ more drugs to outpatients than physicians that do own pharmacies.

The bright-line of the safe harbor exception appears to be misguided as appear to be no evidence economies of scope efficiency justifications from the integration of pharmacies into physician practices. Specifically, we do not find that the convenience of collecting one's prescriptions before leaving the physician office improves adherence to drug therapy among diabetic and chronically ill hypertensive patients. Nor do we find that integration 
improves coordination of care enough to reduce adverse events for patients with diabetes, hypertension or ARI.

Providing safe harbor exceptions ultimately voids the very purpose of the original prohibition as physicians exploit these loopholes to continue to engage in profitable selfreferrals. The "safe harbor" exemption only encourages physicians to integrate complementary into their practices thereby increasing costs from moral hazard without any off setting gains in efficiency from economies of scope. 


\section{References}

Afendulis, CC and DP Kessler. 2007. "Tradeoffs from Integrating Diagnosis and Treatment in Markets for Health Care." The American Economic Review, 97(3), 1013-20.

Aronovitz, L. G. 1994. "Referrals to Physician-Owned Imaging Facilities Warrant HCFA Scrutiny: GAO Report to the U.S. House of Representatives." Washington, DC: GAO, 5, 95-2.

Cheng, T.M. 2003. "Taiwan's New National Health Insurance Program." Health Aff, 22(3), 61-76.

Chevalier, J and G Ellison. 1997. "Risk Taking by Mutual Funds as a Response to Incentives." Journal of Political Economy, 105(6), 1167-200.

Childs, A. W. and E. D. Hunter. 1972. "Non-Medical Factors Influencing Use of Diagnostic X-Ray by Physicians." Med Care, 10(4), 323-35.

Chou, Y. J.; W. C. Yip; C. H. Lee; N. Huang; Y. P. Sun and H. J. Chang. 2003. "Impact of Separating Drug Prescribing and Dispensing on Provider Behaviour: Taiwan's Experience." Health Policy and Planning, 18(3), 316-29.

DiMatteo, MR; PJ Giordani; HS Lepper and TW Croghan. 2002. "Patient Adherence and Medical Treatment Outcomes a Meta-Analysis." Medical Care, 40(9), 794-811.

Dranove, D. 1988. "Demand Inducement" Economic Inquiry, 26(2), 281-98.

Eggleston, Karen ed. 2009. Pharmaceutical Policy in the Asia-Pacific. Brookings Institution Press.

Fuchs, V. R. 1978. "The Supply of Surgeons and the Demand for Operations." JHR, 13(0), 35-56.

Gazelle, GS; EF Halpern; HS Ryan and AC Tramontano. 2007. "Utilization of Diagnostic Medical Imaging: Radiologist Referral Versus Same-Specialty Referral." Radiology, 245(2), 517.

Gruber, Jonathan and Maria Owings. 1996. "Physician Financial Incentives and Cesarean Section Delivery." Rand Journal of Economics, 27(1), 99-123.

Hillman, B. J.; C. A. Joseph; M. R. Mabry; J. H. Sunshine; S. D. Kennedy and M. Noether. 1990. "Frequency and Costs of Diagnostic Imaging in Office Practice--a Comparison of SelfReferring and Radiologist-Referring Physicians." New England Journal of Medicine, 323(23), 1604.

Hillman, B.J.; G.T. Olson; R.W. Colbert and L.B. Bernhardt. 1995. "Responses to Denying Charges for Diagnostic Imaging by Nonradiologist Physicians." JAMA, 274(11), 885-87.

Hillman, B. J.; G. T. Olson; P. E. Griffith; J. H. Sunshine; C. A. Joseph; S. D. Kennedy; W. R. Nelson and L. B. Bernhardt. 1992. "Physicians' Utilization and Charges for Outpatient Diagnostic Imaging in a Medicare Population." JAMA, 268(15), 2050-54.

Ho, P. M.; J. S. Rumsfeld; F. A. Masoudi; D. L. McClure; M. E. Plomondon; J. F. Steiner and D. J. Magid. 2006. "Effect of Medication Nonadherence on Hospitalization and Mortality among Patients with Diabetes Mellitus." Arch Intern Med, 166(17), 1836-41.

Hubbard, TN. 1998. "An Empirical Examination of Moral Hazard in the Vehicle Inspection Market." Rand Journal of Economics, 29(2), 406-26.

Hubbard, TN. 2002. "How Do Consumers Motivate Experts? Reputational Incentives in an Auto Repair Market." Journal of Law and Economics, 437-68. 
Iizuka, T. 2007. "Experts' Agency Problems: Evidence from the Prescription Drug Market in Japan." The RAND Journal of Economics, 38(3), 844-62.

Lee, Jeannie K.; Karen A. Grace and Allen J. Taylor. 2006. "Effect of a Pharmacy Care Program on Medication Adherence and Persistence, Blood Pressure, and Low-Density Lipoprotein Cholesterol." JAMA: The Journal of the American Medical Association, 296(21), 2563-71.

Levitt, SD and C Syverson. 2008. "Market Distortions When Agents Are Better Informed: The Value of Information in Real Estate Transactions." Review of Economics and Statistics, 90(4), 599-611.

Lu, Jui-Fen Rachel and William C. Hsiao. 2003. "Does Universal Health Insurance Make Health Care Unaffordable? Lessons from Taiwan." Health Aff, 22(3), 77-88.

McGuire, T. G. 2000. Physician Agency.

McGuire, T. G. and M. V. Pauly. 1991. "Physician Response to Fee Changes with Multiple Payers." Journal of Health Economics, 10(4), 385-410.

Mitchell, J. M. 2005. "Effects of Physician-Owned Hospitals." Health Affairs, 24, 481-90.

Mitchell, J. M. and T. R. Sass. 1995. "Physician Ownership of Ancillary Services: Indirect Demand Inducement or Quality Assurance?" Journal of Health Economics, 14(3), 263-89.

Mitchell, JM. 2008. "Utilization Trends for Advanced Imaging Procedures: Evidence from Individuals with Private Insurance Coverage in California." Medical Care, 46(5), 460.

Mojtabai, Ramin and Mark Olfson. 2003. "Medication Costs, Adherence, and Health Outcomes among Medicare Beneficiaries." Health Affairs, 22(4), 220-29.

Osterberg, L and Terrence B. 2005. "Adherence to Medication." NEJM, 353(5), 487-97.

Simpson, S. H,; D. T. Eurich; S. R. Majumdar; R. S. Padwal; R. T. Tsuyuki; J. Varney and J. A. Johnson. 2006. "A Meta-Analysis of the Association between Adherence to Drug Therapy and Mortality." BMJ, 333(7557), 15.

Sokol, M.C.; K.A. McGuigan; R.R. Verbrugge and R.S. Epstein. 2005. "Impact of Medication Adherence on Hospitalization Risk and Healthcare Cost." Medical Care, 43(6), 521.

Strasser, R. P.; M. J. Bass and M. Brennan. 1987. "The Effect of an on-Site Radiology Facility on Radiologic Utilization in Family Practice." J Fam Pract, 24(6), 619-23.

Tabor, P.A. and D.A. Lopez. 2004. "Comply with Us: Improving Medication Adherence." Journal of Pharmacy Practice, 17(3), 167-81.

Taylor, C. R. 1995. "The Economics of Breakdowns, Checkups, and Cures." JPE, 103(1), 53.

Tynan, A; RA Berenson and JB Christianson. 2008. "Health Plans Target Advanced Imaging Services: Cost, Quality and Safety Concerns Prompt Renewed Oversight." Issue brief (Center for Studying Health System Change), (118), 1.

United States Government Accountability Office. 2008. "Rapid Spending Growth and Shift to Physician Offices Indicate Need for Additional Management Practices," U. S. G. A. Office,

Wagstaff, Adam. 2007. "Health Systems in East Asia: What Can Developing Countries Learn from Japan and the Asian Tigers?" Health Economics, 16(5), 441-56. 
Wolinsky, A. 1993. "Competition in a Market for Informed Experts' Services." Rand, 24(3), 38098.

Wu, P.H.; C.Y. Yang; Z.L. Yao; W.Z. Lin; L.W. Wu and C.C. Chang. 2009. " Blood Pressure Control and Hospitalization to Medication Adherence among Patients with Hypertension in Taiwan." American journal of hypertension, 23(2), 155-60. 
Table 1: Baseline (1997) Means for Clinics by Integration Status

Prior to Separating Policy Implementation

\begin{tabular}{|c|c|c|c|}
\hline & $\begin{array}{l}\text { Not integrated } \\
\quad \text { in } 1997\end{array}$ & $\begin{array}{c}\text { Integrated in } \\
1997\end{array}$ & Difference \\
\hline \multicolumn{4}{|l|}{ Panel A: Office Visit Characteristics } \\
\hline Patient is female & 0.57 & 0.55 & 0.02 \\
\hline Patient age & 33.09 & 28.61 & $4.48^{* * *}$ \\
\hline Respiratory illness & 0.42 & 0.45 & -0.03 \\
\hline Any drug prescription & 0.98 & 0.98 & 0 \\
\hline Antacids/absorbents prescribed & 0.19 & 0.24 & -0.05 \\
\hline Anti-inflammatory prescribed & 0.15 & 0.19 & -0.04 \\
\hline Analgesics/Antipyretics prescribed & 0.32 & 0.36 & -0.04 \\
\hline Expectorant prescribed & 0.04 & 0.05 & -0.01 \\
\hline Drug expenditures & 88.07 & 92.55 & -4.48 \\
\hline Diagnostic test ordered & 0.03 & 0.03 & 0 \\
\hline Diagnostic test expenditures & 238.76 & 259.24 & -20.48 \\
\hline Physician services expenditures & 244.28 & 239.00 & 5.28 \\
\hline Total expenditures & 377.48 & 352.54 & 24.94 \\
\hline Number of observations & 65,964 & 96,669 & \\
\hline \multicolumn{4}{|l|}{ Panel B: Clinic characteristics } \\
\hline Monthly practice volume (visits) & $1,591.34$ & $2,650.85$ & ${\stackrel{-}{1,059.51^{* * *}}}^{*}$ \\
\hline Monthly revenues (in 1000 NT\$) & 686.80 & $1,085.11$ & $-398.31 * * *$ \\
\hline Number of observations & 3,420 & 1,826 & \\
\hline
\end{tabular}

Notes: The sample is visits to clinics by patients between older than 3 and younger than 60 for diagnoses covered under the separating policy. Integrated is defined as having onsite pharmacy prior to the implementation of the separating policy in the township in which the clinic is located. Expenditures are reported in 1997 New Taiwanese Dollars. Expenditures for drugs and diagnostic tests are conditional on positive expenditure. Statistical significance levels for tests of the null hypothesis that the difference in means is zero are marked as $* * *$ indicating $\mathrm{p}<$ 0.01 and ${ }^{* *}$ indicating $\mathrm{p}<0.05$. The hypothesis tests are conducted clustering standard errors at the township level. 
Table 2: Reduced Form Impact of Separating Policy

\begin{tabular}{|c|c|c|c|c|c|c|}
\hline & Any Prescription & $\begin{array}{c}\text { Log drug } \\
\text { expenditures }\end{array}$ & $\begin{array}{c}\text { Any Diagnostic } \\
\text { Test }\end{array}$ & $\begin{array}{l}\text { Log diagnostic } \\
\text { expenditures }\end{array}$ & $\begin{array}{l}\text { Log physician } \\
\text { services } \\
\text { expenditures }\end{array}$ & $\begin{array}{l}\text { Log total } \\
\text { expenditures }\end{array}$ \\
\hline \multicolumn{7}{|c|}{ Panel A: Sample of visits to all clinics by non-infant and non-elderly patients } \\
\hline Treatment & $\begin{array}{c}\mathbf{- 0 . 0 1 4} * * * \\
(0.002)\end{array}$ & $\begin{array}{c}-\mathbf{0 . 0 3 8 * *} \\
(0.018)\end{array}$ & $\begin{array}{l}\mathbf{0 . 0 0 3} * * \\
(0.001)\end{array}$ & $\begin{array}{l}-0.024 \\
(0.022)\end{array}$ & $\begin{array}{c}0.000 \\
(0.002)\end{array}$ & $\begin{array}{c}-\mathbf{0 . 0 1 3} * * * \\
(0.005)\end{array}$ \\
\hline Mean & 0.97 & 96.15 & 0.04 & 255.14 & 254.31 & 377.31 \\
\hline Observations & 871,319 & 641,627 & 871,319 & 35,030 & 871,319 & 673,899 \\
\hline \# Physicians & 8,821 & 8,144 & 8,821 & 3,494 & 8,821 & 8,399 \\
\hline \multicolumn{7}{|c|}{ Panel B: Sample of visits to clinics not integrated at baseline by non-infant and non-elderly patients } \\
\hline Treatment & $\begin{array}{c}-\mathbf{0 . 0 1 2} * * * \\
(0.002)\end{array}$ & $\begin{array}{c}-0.024 \\
(0.018)\end{array}$ & $\begin{array}{c}0.003 \\
(0.002)\end{array}$ & $\begin{array}{l}-0.014 \\
(0.024)\end{array}$ & $\begin{array}{l}-0.004 \\
(0.002)\end{array}$ & $\begin{array}{c}-\mathbf{0 . 0 1 6}{ }^{* * *} \\
(0.005)\end{array}$ \\
\hline Mean & 0.96 & 95.51 & 0.04 & 247.19 & 266.29 & 388.03 \\
\hline Observations & 428,205 & 308,602 & 428,205 & 18,457 & 428,205 & 329,895 \\
\hline \# Physicians & 6,097 & 5,462 & 6,097 & 2,130 & 6,097 & 5,710 \\
\hline \multicolumn{7}{|c|}{ Panel C: Falsification test - Sample of visits to all clinics by infants and elderly patients exempt from separating policy } \\
\hline Treatment & $\begin{array}{l}-0.004 \\
(0.003)\end{array}$ & $\begin{array}{c}-0.002 \\
(0.026)\end{array}$ & $\begin{array}{c}-0.001 \\
(0.002)\end{array}$ & $\begin{array}{c}0.031 \\
(0.086)\end{array}$ & $\begin{array}{l}-0.001 \\
(0.004)\end{array}$ & $\begin{array}{l}-0.004 \\
(0.008)\end{array}$ \\
\hline Mean & 0.97 & 91.63 & 0.03 & 225.78 & 275.32 & 394.92 \\
\hline Observations & 135,605 & 97,376 & 135,605 & 4,226 & 135,605 & 101,203 \\
\hline \# Physicians & 7,382 & 6,682 & 7,382 & 1,569 & 7,382 & 6,839 \\
\hline
\end{tabular}

Notes: Each column of each panel reports the coefficient and standard error of the difference in difference estimate of the effect of the separating policy on the dependent variable controlling for clinic fixed effects, quarter by municipality fixed effects, patient age, patient sex, and patient diagnosis. Each column represents a different dependent variable and each panel a different sample. The standard errors are clustered at the township level. Statistical significance levels for tests of the null hypothesis that the coefficient estimate is zero are marked as ${ }^{* * *}$ indicating $\mathrm{p}<0.01$ and ${ }^{* *}$ indicating $\mathrm{p}<0.05$. 
Table 3: Baseline (1997) Means for Clinics Not Integrated at Baseline by Integration Status in 2000 Post Separating Policy Implementation

\begin{tabular}{|c|c|c|c|}
\hline & $\begin{array}{c}\text { Not } \\
\text { integrated } \\
\text { in } 2000 \\
\end{array}$ & $\begin{array}{l}\text { Integrated } \\
\text { in } 2000\end{array}$ & Difference \\
\hline \multicolumn{4}{|l|}{ Panel A: Office Visit Characteristics } \\
\hline Patient is female & 0.56 & 0.58 & -0.02 \\
\hline Patient age & 35.06 & 29.65 & $5.40^{* * *}$ \\
\hline Respiratory illness & 0.40 & 0.45 & -0.05 \\
\hline Any drug prescription & 0.98 & 0.98 & 0 \\
\hline $\begin{array}{r}\text { Antacids/absorbents } \\
\text { prescribed }\end{array}$ & 0.20 & 0.18 & 0.02 \\
\hline Anti-inflammatory prescribed & 0.15 & 0.15 & 0 \\
\hline $\begin{array}{r}\text { Analgesics/Antipyretics } \\
\text { prescribed }\end{array}$ & 0.12 & 0.11 & 0.01 \\
\hline Expectorant prescribed & 0.04 & 0.04 & 0 \\
\hline Drug expenditures & 88.91 & 86.46 & 2.45 \\
\hline Diagnostic test ordered & 0.03 & 0.03 & 0.00 \\
\hline Diagnostic test expenditures & 229.06 & 251.09 & -22.03 \\
\hline Physician service expenditures & 248.89 & 236.18 & 12.71 \\
\hline Total expenditures & 384.40 & 364.34 & 20.06 \\
\hline Number of observations & 41,896 & 24,106 & \\
\hline \multicolumn{4}{|l|}{ Panel B: Clinic characteristics } \\
\hline $\begin{array}{r}\text { Monthly practice volume } \\
\text { (visits) }\end{array}$ & $1,265.11$ & $2,121.52$ & $-856.41^{* * *}$ \\
\hline $\begin{array}{r}\text { Monthly revenues (in } 1000 \\
\text { NT\$) }\end{array}$ & 637.86 & 767.82 & $-129.96^{* *}$ \\
\hline Number of observations & 3,420 & 2,128 & 1,298 \\
\hline
\end{tabular}

Notes: The sample is visits to clinics not integrated at baseline by patients between older than 3 and younger than 60 for diagnoses covered under the separating policy. Integrated is defined as having an onsite pharmacy in 2000 after to the implementation of the separating policy in township in which the clinic is located. Expenditures are reported in 1997 New Taiwanese Dollars. Expenditures for drugs and diagnostic tests are conditional on positive expenditure. Statistical significance levels for tests of the null hypothesis that the difference in means is zero are marked as ${ }^{* * *}$ indicating $\mathrm{p}<0.01$ and ${ }^{* *}$ indicating $\mathrm{p}<$ 0.05 . The hypothesis tests are conducted clustering standard errors at the township level. 
Table 4: Impact of the Separating Policy on Probability a Clinic Integrates

\begin{tabular}{lcc}
\hline & Model $(1)$ & Model $(2)$ \\
\hline Treatment & $\begin{array}{c}\mathbf{0 . 6 6 0 * * *} \\
(\mathbf{0 . 0 1 1})\end{array}$ & $\begin{array}{c}\mathbf{0 . 0 9 0} \\
\mathbf{( 0 . 0 4 3}\end{array}$ \\
Treat $\times \mathrm{D}_{25-50 \% \text { tile }} \dagger$ & & $\begin{array}{c}\mathbf{0 . 1 9 6 * * *} \\
\mathbf{( 0 . 0 2 1 )}\end{array}$ \\
Treatment $\times \mathrm{D}_{50-75 \% \text { tile }} \dagger$ & & $\mathbf{0 . 4 3 0 * * *}$ \\
& & $\mathbf{( 0 . 0 2 1 )}$ \\
Treatment $\times \mathrm{D}_{75-100 \% \text { tile }} \dagger$ & & $\mathbf{0 . 8 8 7 * * *}$ \\
& & $\mathbf{( 0 . 0 2 0 )}$ \\
Number of observations & 3,916 & 3,916 \\
R-squared & 0.56 & 0.72 \\
\hline
\end{tabular}

Notes: The coefficient and standard error are the difference in difference estimate of the effect of the separating policy on the probability a clinic integrates controlling for clinic fixed effects and quarter-year effects. The unit of observation is the clinic and the sample is that set of clinics that were not integrated prior to the implementation of the separating policy. The standard errors are clustered at the township level. Statistical significance levels for tests of the null hypothesis that the coefficient estimate is zero are marked as ${ }^{* * *}$ indicating $\mathrm{p}<0.01$ and ${ }^{* *}$ indicating $\mathrm{p}<0.05$. 
Table 5: Impact of Separating Policy on Clinics by Integration Choice

\begin{tabular}{|c|c|c|c|c|c|c|}
\hline & $\begin{array}{c}\text { Any } \\
\text { Prescription }\end{array}$ & $\begin{array}{c}\text { Log drug } \\
\text { expenditures }\end{array}$ & $\begin{array}{c}\text { Any diagnostic } \\
\text { tests }\end{array}$ & $\begin{array}{l}\text { Log diagnostic } \\
\text { expenditures }\end{array}$ & $\begin{array}{l}\text { Log physician } \\
\text { expenditures }\end{array}$ & $\begin{array}{c}\text { Log total } \\
\text { expenditures }\end{array}$ \\
\hline \multicolumn{7}{|l|}{ Panel A: Triple Differences } \\
\hline \multirow[b]{2}{*}{ (b) Treatment $\times$ Pharmacy } & $\begin{array}{c}-\mathbf{0 . 0 2 1} \\
(0.002)\end{array}$ & $\begin{array}{c}\mathbf{- 0 . 0 4 9} * * \\
(0.022)\end{array}$ & $\begin{array}{c}\mathbf{0 . 0 0 5}{ }^{* * *} \\
(0.002)\end{array}$ & $\begin{array}{l}-0.020 \\
(0.025)\end{array}$ & $\begin{array}{l}-0.000 \\
(0.002)\end{array}$ & $\begin{array}{c}-\mathbf{0 . 0 1 8} \mathbf{8}^{* * *} \\
(0.006)\end{array}$ \\
\hline & $\begin{array}{c}\mathbf{0 . 0 1 9} * * * \\
(0.003)\end{array}$ & $\begin{array}{c}0.030 \\
(0.018)\end{array}$ & $\begin{array}{l}-0.004 \\
(0.002)\end{array}$ & $\begin{array}{l}-0.010 \\
(0.024)\end{array}$ & $\begin{array}{c}0.000 \\
(0.002)\end{array}$ & $\begin{array}{c}\mathbf{0 . 0 1 4}^{* * *} \\
(0.005)\end{array}$ \\
\hline$(a)+(b)$ & $\begin{array}{l}-0.002 \\
(0.002)\end{array}$ & $\begin{array}{l}-0.018 \\
(0.017)\end{array}$ & $\begin{array}{c}0.001 \\
(0.002)\end{array}$ & $\begin{array}{l}-0.009 \\
(0.025)\end{array}$ & $\begin{array}{c}0.000 \\
(0.002)\end{array}$ & $\begin{array}{c}-0.004 \\
(0.005)\end{array}$ \\
\hline Observations & 871,319 & 641,627 & 871,319 & 35,030 & 871,319 & 673,899 \\
\hline \multicolumn{7}{|c|}{ Panel B: Instrumental Variable Triple Differences } \\
\hline \multirow[b]{2}{*}{ (b) Treatment $\times$ Pharmacy } & $\begin{array}{c}-\mathbf{0 . 0 2 7 0} \\
(0.003)\end{array}$ & $\begin{array}{c}-\mathbf{0 . 0 4 9 * *} \\
(0.025)\end{array}$ & $\begin{array}{c}\mathbf{0 . 0 0 6}^{* * *} \\
(0.002)\end{array}$ & $\begin{array}{l}-0.037 \\
(0.033)\end{array}$ & $\begin{array}{c}0.004 \\
(0.003)\end{array}$ & $\begin{array}{c}-\mathbf{0 . 0 1 8 0} \\
(0.007)\end{array}$ \\
\hline & $\begin{array}{c}\mathbf{0 . 0 3 3}^{* * *} \\
(0.005)\end{array}$ & $\begin{array}{c}\mathbf{0 . 1 0 6} * * \\
(0.046)\end{array}$ & $\begin{array}{l}-0.004 \\
(0.004)\end{array}$ & $\begin{array}{c}0.019 \\
(0.058)\end{array}$ & $\begin{array}{c}-0.004 \\
(0.006)\end{array}$ & $\begin{array}{c}0.041^{* * *} \\
(0.013)\end{array}$ \\
\hline$(a)+(b)$ & $\begin{array}{c}0.006 \\
(0.003)\end{array}$ & $\begin{array}{c}\mathbf{0 . 0 5 8}^{* *} \\
(0.032)\end{array}$ & $\begin{array}{c}0.002 \\
(0.003)\end{array}$ & $\begin{array}{l}-0.179 \\
(0.040)\end{array}$ & $\begin{array}{l}-0.001 \\
(0.004)\end{array}$ & $\begin{array}{c}\mathbf{0 . 0 2 3}^{* * *} \\
(0.009)\end{array}$ \\
\hline Observations & 751,004 & 543,114 & 751,004 & 27,836 & 751,004 & 569,665 \\
\hline \multicolumn{7}{|c|}{ Panel C: Falsification Tests (Sample of patients exempt from policy) } \\
\hline \multirow[b]{2}{*}{ (b) Treatment $\times$ Pharmacy } & $\begin{array}{c}-\mathbf{0 . 0 0 7} * * \\
(0.003)\end{array}$ & $\begin{array}{l}-0.002 \\
(0.029)\end{array}$ & $\begin{array}{l}-0.003 \\
(0.003)\end{array}$ & $\begin{array}{c}0.094 \\
(0.099)\end{array}$ & $\begin{array}{l}-0.002 \\
(0.004)\end{array}$ & $\begin{array}{l}-0.009 \\
(0.000)\end{array}$ \\
\hline & $\begin{array}{c}\mathbf{0 . 0 0 7}^{* *} \\
(0.003)\end{array}$ & $\begin{array}{c}0.001 \\
(0.028)\end{array}$ & $\begin{array}{c}0.001 \\
(0.003)\end{array}$ & $\begin{array}{c}-0.162 \\
(0.093)\end{array}$ & $\begin{array}{c}0.001 \\
(0.005)\end{array}$ & $\begin{array}{c}0.011 \\
(0.009)\end{array}$ \\
\hline$(a)+(b)$ & $\begin{array}{c}-0.000 \\
(0.003)\end{array}$ & $\begin{array}{c}-0.001 \\
(0.030)\end{array}$ & $\begin{array}{c}-0.001 \\
(0.003)\end{array}$ & $\begin{array}{c}-0.068 \\
(0.095)\end{array}$ & $\begin{array}{c}-0.001 \\
(0.005)\end{array}$ & $\begin{array}{c}0.003 \\
(0.010)\end{array}$ \\
\hline Observations & 135,605 & 97,376 & 135,605 & 4,226 & 135,605 & 101,203 \\
\hline
\end{tabular}

Notes: Treatment (a) is the estimated impact of the separating policy on clinics that did not integrate and (a) $+(\mathrm{b})$ is the estimate of the separating policy on clinics that choose to integrate. Panel A reports the triple difference estimate of the effect of the separating policy on the dependent variable listed at the top of the column controlling for physician fixed effects, quarter-year for each township fixed effects, diagnosis fixed effects, and patient age and sex for the sample of patients covered by the separating policy. Panel B reports the IV triple difference estimates uses baseline patient volume as the instrument for integration for the sample. Panel C reports the triple difference estimates for the sample of patients exempt from the separating policy. The standard errors are clustered at the physician level and ${ }^{* * *} \mathrm{p}<0.01,{ }^{* *} \mathrm{p}<0.05$ for the test of the null hypothesis that the coefficient is different from zero. 
Table 6: Triple Difference Estimate of Policy Impact on Medication Adherence Measured by the Proportion of Days Having Prescribed Medication in Last 90 Days.

\begin{tabular}{rcc}
\hline & Diabetes & $\begin{array}{c}\text { Hypertension } \\
\text { (> 12 visits) }\end{array}$ \\
\hline (a) Treatment & -0.018 & -0.014 \\
& $(0.018)$ & $(0.013)$ \\
(b) Treatment $\times$ pharmacy $+(b)$ & 0.002 & 0.018 \\
& $(0.016)$ & $0.011)$ \\
Observations & 0.006 & 0.005 \\
Number of patients & $(0.016)$ & $(0.009)$ \\
Number of Clinics & 86,915 & 103,933 \\
1997 baseline mean PDC & 8,575 & 3,885 \\
\hline
\end{tabular}

Notes: Treatment is the triple difference estimate of the effect of the separating policy on the proportion of days the patient has prescribed medication for their illness controlling for physician fixed effects, quarter-year for each township fixed effects, diagnosis fixed effects, and patient age and sex. The standard errors are clustered at the physician level and ${ }^{* * *} \mathrm{p}<0.01,{ }^{* *} \mathrm{p}<0.05$ for the test of the null hypothesis that the coefficient is different from zero. Diabetes includes all diagnoses with an ICD9CM code of 249 or 250. Hypertension includes all diagnoses with an ICD9CM code of 401-405. 
Table 7: Effects of the Separating Policy on Adverse Health Events

\begin{tabular}{|c|c|c|c|c|}
\hline & \multicolumn{2}{|c|}{$\begin{array}{l}\text { Panel A: Reduced Form } \\
\text { Difference in Differences }\end{array}$} & \multicolumn{2}{|c|}{$\begin{array}{c}\text { Panel B: By Integration Status } \\
\text { Triple Differences }\end{array}$} \\
\hline & ER visit & Hospitalized & ER visit & Hospitalized \\
\hline \multicolumn{5}{|c|}{ Panel A: Patients with Acute Respiratory Infections, 30-day follow-up ( $N=261,400$ ) } \\
\hline \multirow[b]{2}{*}{ (b) Treatment $\times$ Pharmacy } & $\begin{array}{l}-0.0001 \\
(0.0002)\end{array}$ & $\begin{array}{c}0.0001 \\
(0.0006)\end{array}$ & $\begin{array}{c}0.0005 \\
(0.0004)\end{array}$ & $\begin{array}{c}0.0004 \\
(0.0012)\end{array}$ \\
\hline & & & $\begin{array}{r}-0.0008 \\
(0.0006)\end{array}$ & $\begin{array}{l}-0.0001 \\
(0.0012)\end{array}$ \\
\hline$(\mathrm{a})+(\mathrm{b})$ & & & $\begin{array}{l}-0.0003 \\
(0.0002)\end{array}$ & $\begin{array}{c}0.0003 \\
(0.0008)\end{array}$ \\
\hline 1997 baseline mean & 0.0001 & 0.003 & 0.00013 & 0.0026 \\
\hline \multicolumn{5}{|c|}{ Panel B: Patients with Diabetes Mellitus, 360-day follow-up ( $N=14,001$ ) } \\
\hline (a) Treatment & $\begin{array}{c}0.00003 \\
(0.00146)\end{array}$ & $\begin{array}{c}-0.00000 \\
(0.022)\end{array}$ & $\begin{array}{c}0.0005 \\
(0.0016)\end{array}$ & $\begin{array}{c}0.0113 \\
(0.0301)\end{array}$ \\
\hline (a) Treatment & & & $\begin{array}{l}-0.0006 \\
(0.0016)\end{array}$ & $\begin{array}{l}-0.0138 \\
(0.0311)\end{array}$ \\
\hline$(\mathrm{a})+(\mathrm{b})$ & & & $\begin{array}{l}-0.0001 \\
(0.0016)\end{array}$ & $\begin{array}{l}-0.0024 \\
(0.0242)\end{array}$ \\
\hline 1997 baseline mean & 0.00040 & 0.16000 & 0.000408 & 0.16 \\
\hline \multicolumn{5}{|c|}{ Panel C: Patients with Hypertension 360-day follow-up ( $N=35,895)$} \\
\hline \multirow[b]{2}{*}{ (b) Treatment $\times$ Pharmacy } & $\begin{array}{l}-0.0017 \\
(0.0022)\end{array}$ & $\begin{array}{l}-0.0063 \\
(0.0099)\end{array}$ & $\begin{array}{l}-0.0014 \\
(0.0025)\end{array}$ & $\begin{array}{l}-0.0217 \\
(0.0155)\end{array}$ \\
\hline & & & $\begin{array}{l}-0.0005 \\
(0.0017)\end{array}$ & $\begin{array}{c}0.0177 \\
(0.0153)\end{array}$ \\
\hline$(\mathrm{a})+(\mathrm{b})$ & & & $\begin{array}{l}-0.0018 \\
(0.0023)\end{array}$ & $\begin{array}{l}-0.0041 \\
(0.0108)\end{array}$ \\
\hline 1997 baseline mean & 0.0024 & 0.1480 & 0.0024 & 0.1504 \\
\hline
\end{tabular}

Notes: Treatment is the triple difference estimate of the effect of the separating policy on the probability having an adverse event for the sample of patient with the illness controlling for physician fixed effects, quarter-year for each municipality fixed effects, diagnosis fixed effects, and patient age and sex. The standard errors are clustered at the physician level and ${ }^{* * *} \mathrm{p}<0.01,{ }^{* *}$ $\mathrm{p}<0.05$ for the test of the null hypothesis that the coefficient is different from zero. Diabetes includes all diagnoses with an ICD9CM code of 249 or 250. Hypertension includes all diagnoses with an ICD9CM code of 401-405. Acute Respiratory Infections include all diagnoses with an ICD9CM code of 460-478. 
Figure 1

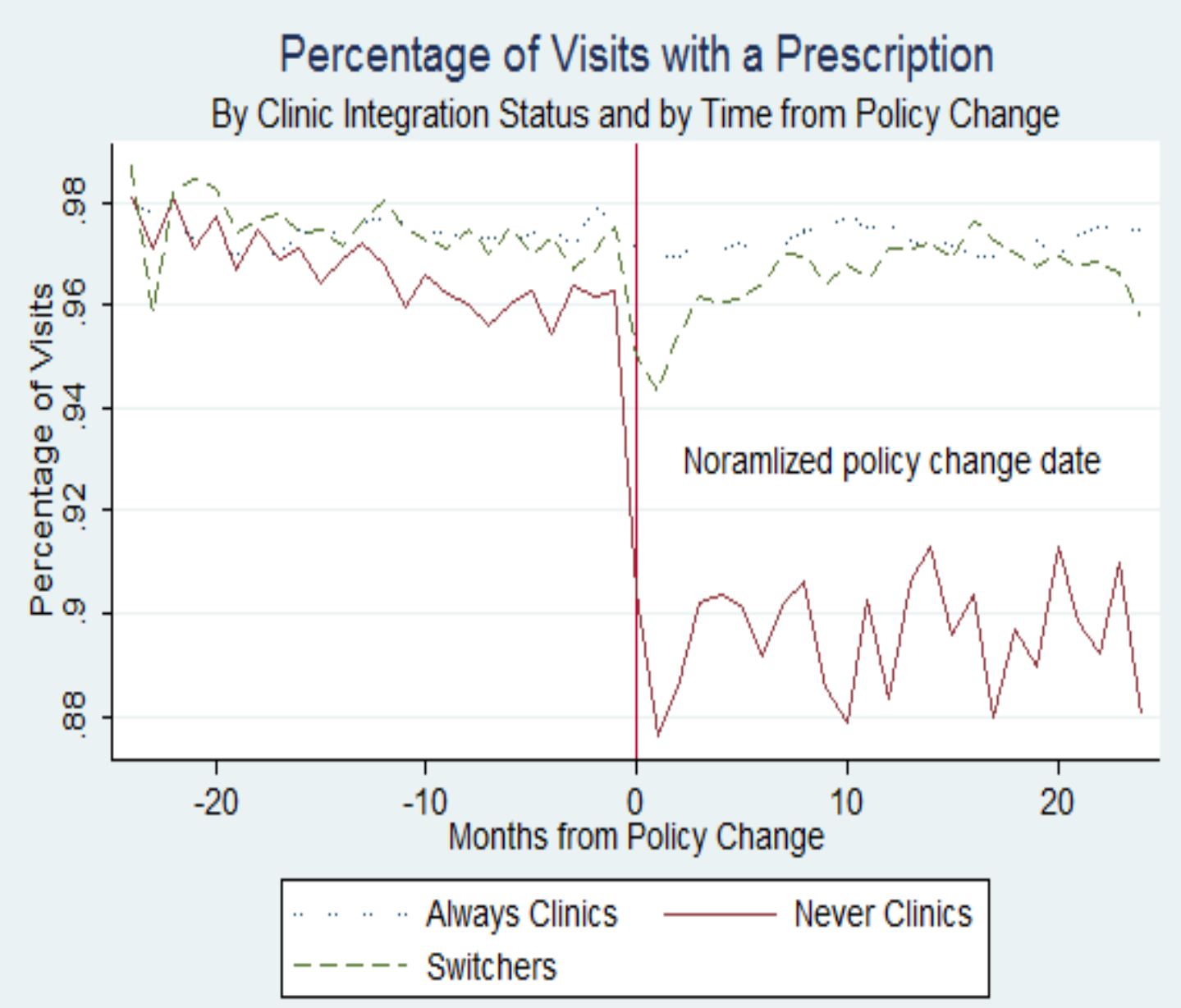


Figure 2

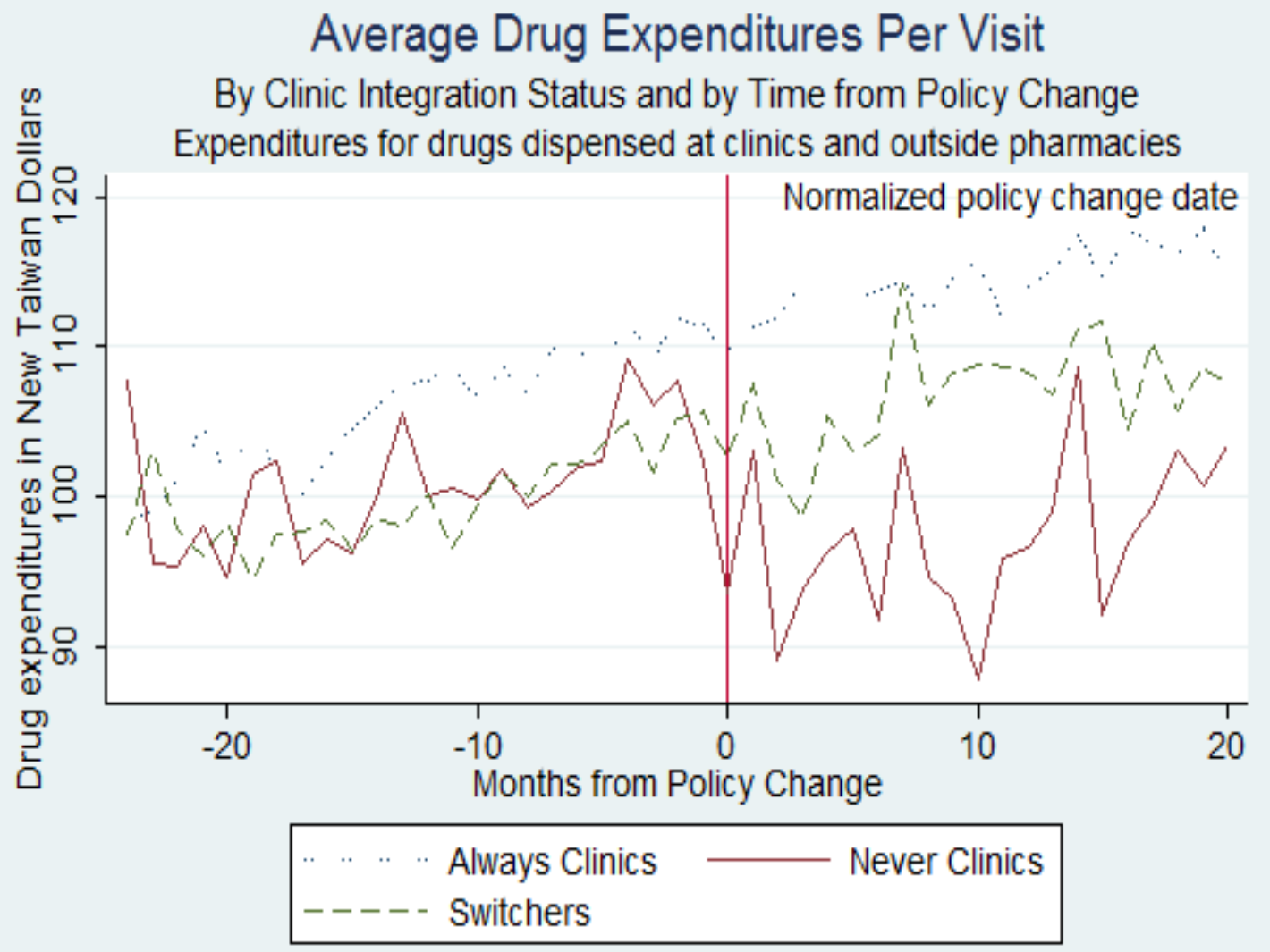

US\$1 $=$ NT\$32. 1-in-500 subsample of all clinic visits, 1997-2000. 
Figure 3

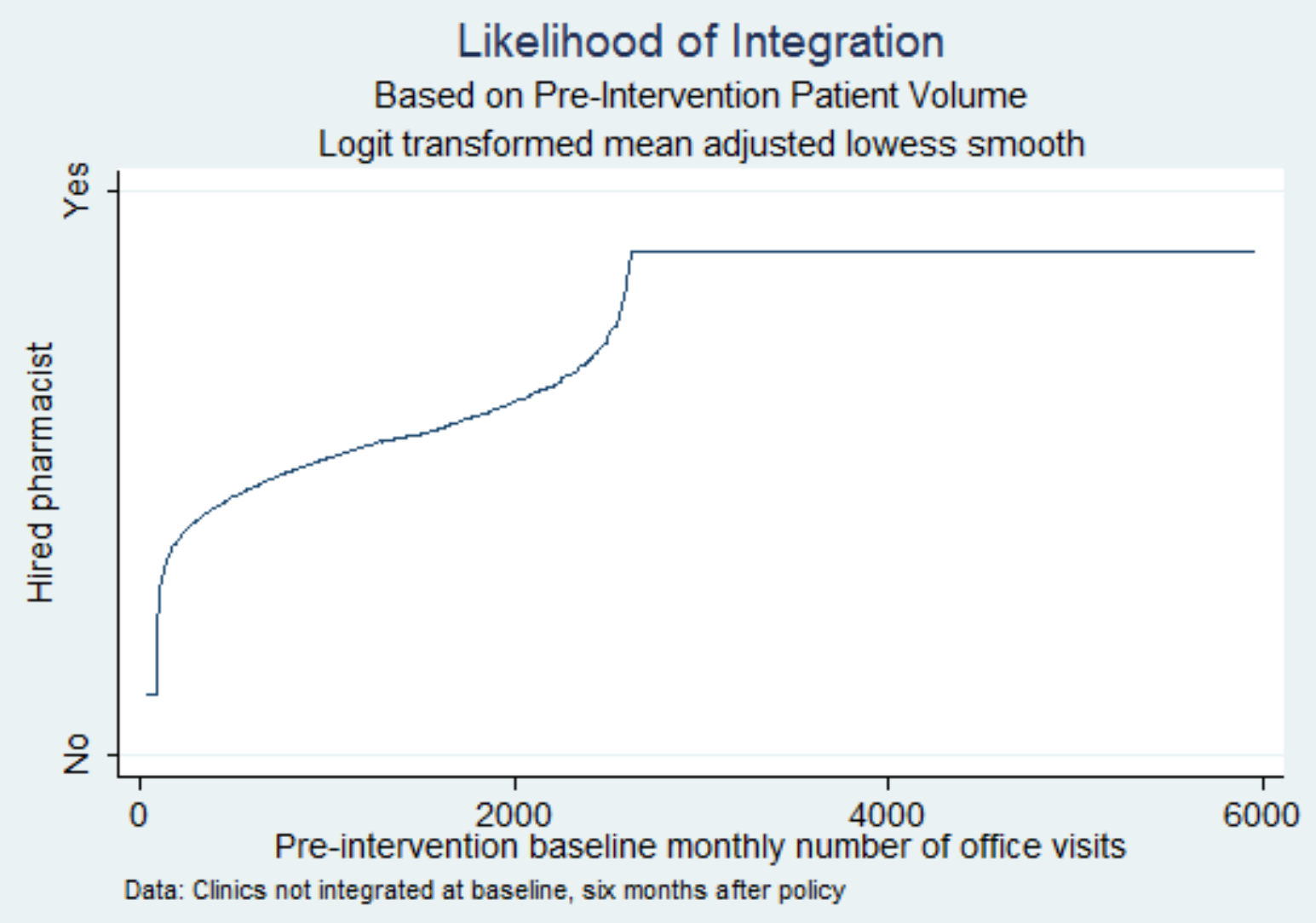


Figure 4

\section{Percentage of Clinics with Onsite Pharmacist}

By Clinic Size and by Time from Policy Change

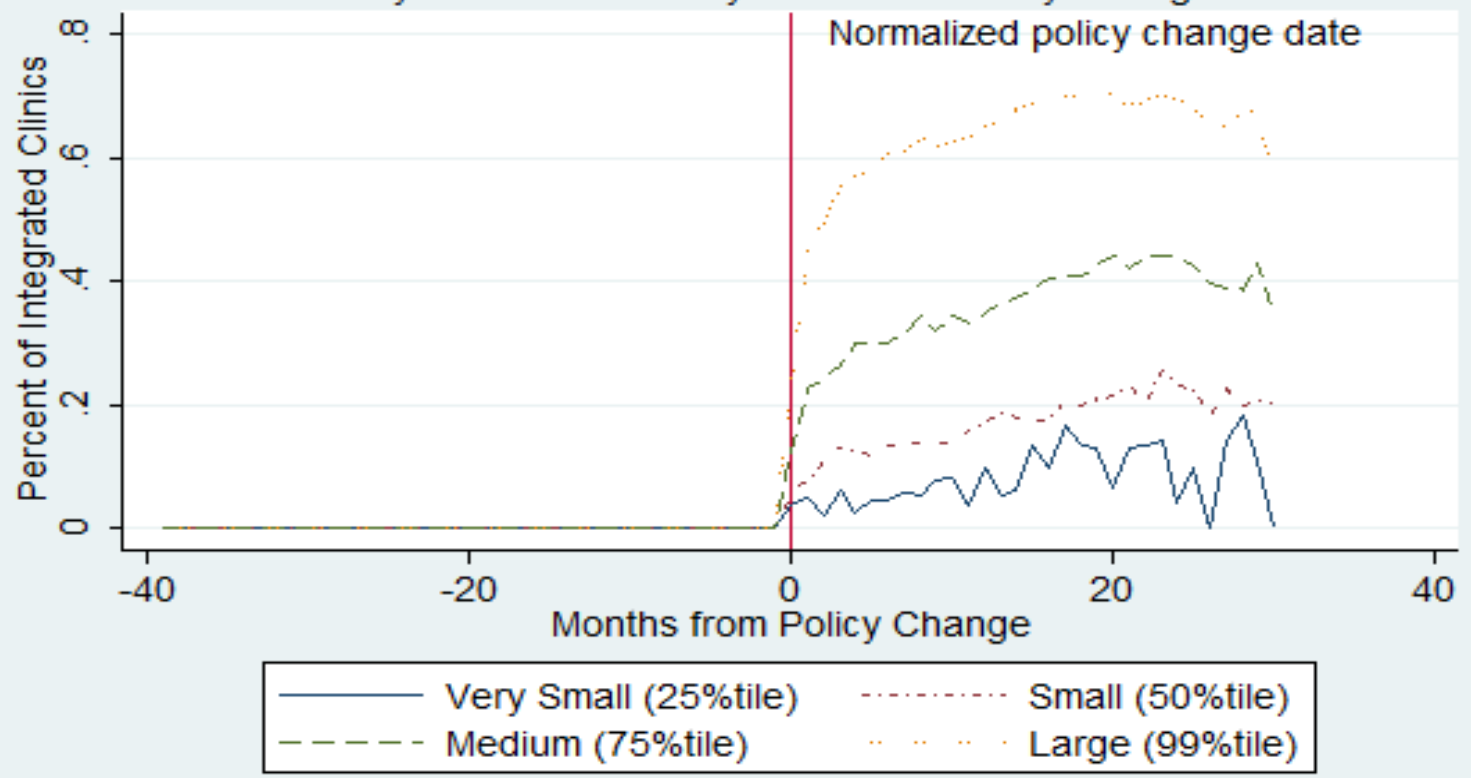

Data: 1 in 500 subsample of all clinics unintegrated at baseline, 1997-2000. 
Figure 5

Percentage of Visits with a Prescription

By Clinic Size and by Time from Policy Change

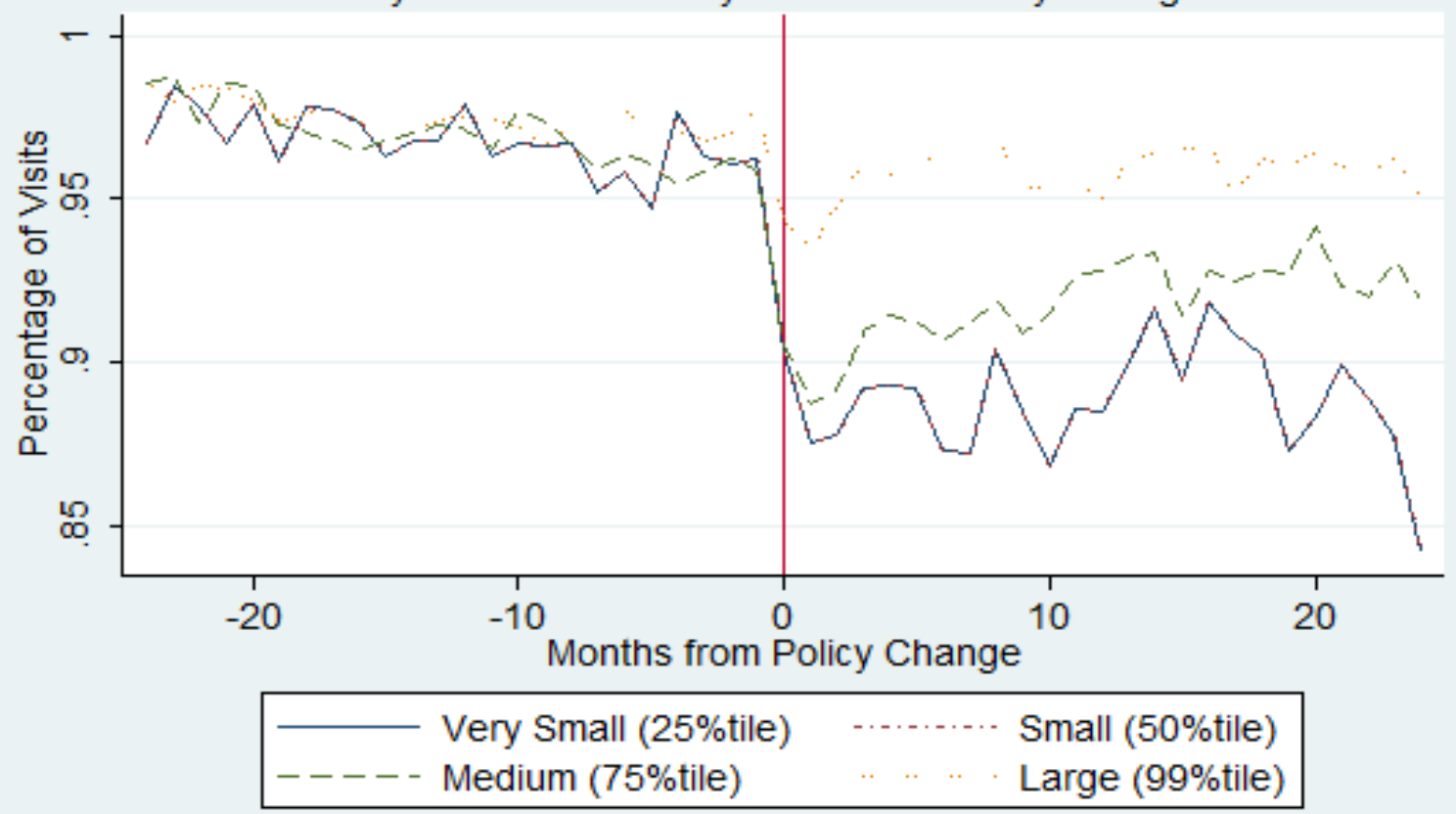

Data: 1-in-500 subsample of all visits at clinics unintegrated at baseline, 1997-2000. 
Figure 6

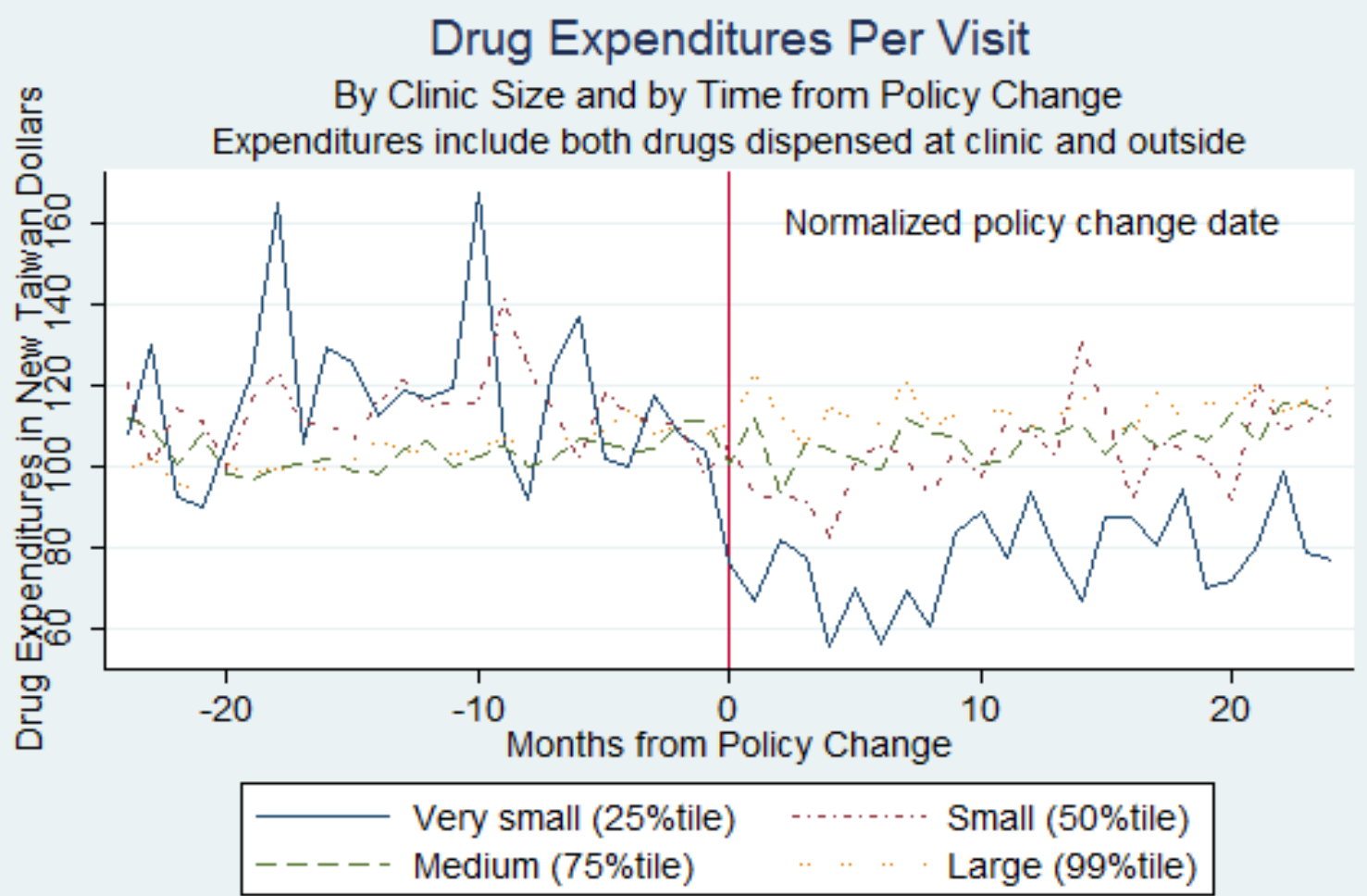

US\$1 $=$ NT\$32. 1-in-500 random subsample includes only clinics not integrated at baseline, 1997-2000. 


\section{APPENDIX TABLES}

Table A1: P-Values for tests equality of pre-intervention trends for treatment \& comparison groups

\begin{tabular}{|c|c|c|c|c|c|}
\hline $\begin{array}{c}\text { Not Integrated prior to } \\
\text { policy } \times \text { Trend } \times \ldots .\end{array}$ & Prescription & $\begin{array}{c}\text { Log drug } \\
\text { expenditures }\end{array}$ & $\begin{array}{c}\text { Diagnostic } \\
\text { tests }\end{array}$ & $\begin{array}{c}\text { Log diagnostic } \\
\text { expenditures }\end{array}$ & $\begin{array}{c}\text { Log total } \\
\text { expenditures }\end{array}$ \\
\hline Municipality 1 & $\begin{array}{c}0.017 \\
(0.016)\end{array}$ & $\begin{array}{c}0.239 \\
(0.193)\end{array}$ & $\begin{array}{c}0.149 \\
(0.091)\end{array}$ & $\begin{array}{l}-0.028 \\
(0.018)\end{array}$ & $\begin{array}{c}0.186 \\
(0.157)\end{array}$ \\
\hline Municipality 2 & $\begin{array}{l}-0.079 \\
(0.067)\end{array}$ & $\begin{array}{l}-0.016 \\
(0.164)\end{array}$ & $\begin{array}{l}-0.153 \\
(0.108)\end{array}$ & $\begin{array}{c}0.493 \\
(0.500)\end{array}$ & $\begin{array}{l}-0.477 \\
(0.297)\end{array}$ \\
\hline Municipality 3 & $\begin{array}{c}-0.001 \\
(0.001)\end{array}$ & $\begin{array}{l}-0.001 \\
(0.006)\end{array}$ & $\begin{array}{c}0.013 \\
(0.008)\end{array}$ & $\begin{array}{l}-0.025 \\
(0.040)\end{array}$ & $\begin{array}{c}0.001 \\
(0.008)\end{array}$ \\
\hline Municipality 4 & $\begin{array}{c}0.000 \\
(0.0017)\end{array}$ & $\begin{array}{c}0.005 \\
(0.004)\end{array}$ & $\begin{array}{c}0.0013 \\
(0.0026)\end{array}$ & $\begin{array}{l}-0.020 \\
(0.022)\end{array}$ & $\begin{array}{c}0.000 \\
(0.005)\end{array}$ \\
\hline Municipality 5 & $\begin{array}{l}-0.003^{*} \\
(0.001)\end{array}$ & $\begin{array}{c}0.005 \\
(0.003)\end{array}$ & $\begin{array}{l}-0.003 \\
(0.003)\end{array}$ & $\begin{array}{l}-0.014 \\
(0.021)\end{array}$ & $\begin{array}{l}-0.000 \\
(0.004)\end{array}$ \\
\hline Municipality 6 & $\begin{array}{c}0.000 \\
(0.000)\end{array}$ & $\begin{array}{c}0.001 \\
(0.002)\end{array}$ & $\begin{array}{l}-0.003 \\
(0.003)\end{array}$ & $\begin{array}{l}-0.008 \\
(0.018)\end{array}$ & $\begin{array}{l}-0.001 \\
(0.003)\end{array}$ \\
\hline Municipality 7 & $\begin{array}{c}-0.001 \\
(0.002)\end{array}$ & $\begin{array}{c}0.0150 * \\
(0.007)\end{array}$ & $\begin{array}{c}0.007 \\
(0.007)\end{array}$ & $\begin{array}{c}0.002 \\
(0.041)\end{array}$ & $\begin{array}{c}0.015 \\
(0.009)\end{array}$ \\
\hline Municipality 8 & $\begin{array}{c}0.000 \\
(0.000)\end{array}$ & $\begin{array}{c}0.000 \\
(0.002)\end{array}$ & $\begin{array}{c}0.002 \\
(0.003)\end{array}$ & $\begin{array}{c}0.000 \\
(0.015)\end{array}$ & $\begin{array}{l}-0.001 \\
(0.004)\end{array}$ \\
\hline Municipality 9 & $\begin{array}{l}-0.000 \\
(0.001)\end{array}$ & $\begin{array}{c}-0.002 \\
(0.002)\end{array}$ & $\begin{array}{c}0.000 \\
(0.002)\end{array}$ & $\begin{array}{l}-0.017 \\
(0.015)\end{array}$ & $\begin{array}{l}-0.005 \\
(0.003)\end{array}$ \\
\hline Municipality 10 & $\begin{array}{l}-0.003 * \\
(0.001)\end{array}$ & $\begin{array}{c}-0.0251 \\
(0.0155)\end{array}$ & $\begin{array}{c}0.008 \\
(0.007)\end{array}$ & $\begin{array}{l}0.090^{*} \\
(0.038)\end{array}$ & $\begin{array}{l}-0.010 \\
(0.017)\end{array}$ \\
\hline Municipality 11 & $\begin{array}{c}0.001 \\
(0.001)\end{array}$ & $\begin{array}{l}-0.003 \\
(0.004)\end{array}$ & $\begin{array}{l}-0.000 \\
(0.004)\end{array}$ & $\begin{array}{l}-0.018 \\
(0.023)\end{array}$ & $\begin{array}{l}-0.011^{*} \\
(0.004)\end{array}$ \\
\hline Municipality 12 & $\begin{array}{c}-0.001 \\
(0.001)\end{array}$ & $\begin{array}{c}0.002 \\
(0.003)\end{array}$ & $\begin{array}{l}-0.003 \\
(0.003)\end{array}$ & $\begin{array}{c}0.016 \\
(0.021)\end{array}$ & $\begin{array}{c}0.000 \\
(0.004)\end{array}$ \\
\hline Municipality 13 & $\begin{array}{c}0.000 \\
(0.001)\end{array}$ & $\begin{array}{l}-0.000 \\
(0.005)\end{array}$ & $\begin{array}{l}-0.003 \\
(0.005)\end{array}$ & $\begin{array}{l}-0.020 \\
(0.033)\end{array}$ & $\begin{array}{l}-0.002 \\
(0.008)\end{array}$ \\
\hline Municipality 14 & $\begin{array}{c}0.001 \\
(0.003)\end{array}$ & $\begin{array}{c}0.006 \\
(0.007)\end{array}$ & $\begin{array}{c}0.008 \\
(0.005)\end{array}$ & $\begin{array}{l}-0.005 \\
(0.050)\end{array}$ & $\begin{array}{c}0.008 \\
(0.008)\end{array}$ \\
\hline Municipality 15 & $\begin{array}{c}0.001 \\
(0.003)\end{array}$ & $\begin{array}{l}-0.023 \\
(0.013)\end{array}$ & $\begin{array}{c}0.013 \\
(0.010)\end{array}$ & $\begin{array}{l}-0.027 \\
(0.086)\end{array}$ & $\begin{array}{l}-0.020 \\
(0.015)\end{array}$ \\
\hline Municipality 16 & $\begin{array}{c}-0.002 \\
(0.002)\end{array}$ & $\begin{array}{l}-0.002 \\
(0.008)\end{array}$ & $\begin{array}{l}-0.009 \\
(0.009)\end{array}$ & $\begin{array}{l}-0.026 \\
(0.048)\end{array}$ & $\begin{array}{c}-0.015 \\
(0.010)\end{array}$ \\
\hline Municipality 17 & $\begin{array}{c}0.000 \\
(0.001)\end{array}$ & $\begin{array}{c}0.001 \\
(0.003)\end{array}$ & $\begin{array}{l}-0.007 * \\
(0.004)\end{array}$ & $\begin{array}{l}-0.009 \\
(0.015)\end{array}$ & $\begin{array}{c}0.000 \\
(0.003)\end{array}$ \\
\hline Municipality 18 & $\begin{array}{c}0.000 \\
(0.001) \\
\end{array}$ & $\begin{array}{l}-0.010^{*} \\
(0.005)\end{array}$ & $\begin{array}{l}-0.004 \\
(0.005)\end{array}$ & $\begin{array}{c}0.022 \\
(0.031) \\
\end{array}$ & $\begin{array}{l}-0.006 \\
(0.006) \\
\end{array}$ \\
\hline $\begin{array}{l}\text { F stat for joint } \\
\text { significance }\end{array}$ & 1.00 & 1.52 & 1.29 & 0.84 & 1.22 \\
\hline Prob > F (p-value) & 0.45 & 0.07 & 0.18 & 0.66 & 0.23 \\
\hline Observations & 265,070 & 257,341 & 265,070 & 60,492 & 257,376 \\
\hline
\end{tabular}

Notes: The coefficients and standard error are from regressions on the dependent variable listed at the top of the column controlling for physician fixed effects, quarter-year for each municipality fixed effects, diagnosis fixed effects, and patient age and sex. The sample is visits to clinics prior to the implementation of the separating policy in the township in which the clinic is located. The standard errors are clustered at the township level and ${ }^{* * *} p<0.01,{ }^{* *} p<0.05$. 
Table A2: P-Values for test of equality of pre-intervention trends for clinics that hire and do not hire an onsite pharmacy in the post intervention period

\begin{tabular}{|c|c|c|c|c|c|}
\hline $\begin{array}{c}\text { Integrated post policy } \times \\
\text { Trend } \times \ldots \\
\end{array}$ & Prescription & $\begin{array}{c}\text { Log drug } \\
\text { expenditures }\end{array}$ & Diagnostic test & $\begin{array}{c}\text { Log diagnostic } \\
\text { expenditures }\end{array}$ & $\begin{array}{c}\text { Log total } \\
\text { expenditures }\end{array}$ \\
\hline Municipality 1 & $\begin{array}{c}0.179 \\
(0.151)\end{array}$ & $\begin{array}{l}-0.0225 \\
(0.0411)\end{array}$ & $\begin{array}{l}-0.281 \\
(0.185)\end{array}$ & $\begin{array}{l}-0.0679 \\
(0.102)\end{array}$ & $\begin{array}{l}0.00955 \\
(0.0222)\end{array}$ \\
\hline Municipality 2 & $\begin{array}{c}0.181 \\
(0.151)\end{array}$ & $\begin{array}{l}-0.0284 \\
(0.0426)\end{array}$ & $\begin{array}{l}-0.282 \\
(0.185)\end{array}$ & $\begin{array}{l}-0.0457 \\
(0.0922)\end{array}$ & $\begin{array}{c}0.0142 \\
(0.0220)\end{array}$ \\
\hline Municipality 3 & $\begin{array}{c}0.181 \\
(0.151)\end{array}$ & $\begin{array}{l}-0.0128 \\
(0.0384)\end{array}$ & $\begin{array}{l}-0.281 \\
(0.185)\end{array}$ & $\begin{array}{l}-0.0139 \\
(0.0724)\end{array}$ & $\begin{array}{c}0.0157 \\
(0.0219)\end{array}$ \\
\hline Municipality 4 & $\begin{array}{c}0.181 \\
(0.151)\end{array}$ & $\begin{array}{l}-0.0261 \\
(0.0310)\end{array}$ & $\begin{array}{l}-0.283 \\
(0.185)\end{array}$ & $\begin{array}{l}-0.0605 \\
(0.0761)\end{array}$ & $\begin{array}{l}0.00791 \\
(0.0220)\end{array}$ \\
\hline Municipality 5 & $\begin{array}{c}0.180 \\
(0.151)\end{array}$ & $\begin{array}{l}-0.00387 \\
(0.0578)\end{array}$ & $\begin{array}{l}-0.274 \\
(0.185)\end{array}$ & $\begin{array}{c}-0.120 \\
(0.0921)\end{array}$ & $\begin{array}{c}0.0113 \\
(0.0219)\end{array}$ \\
\hline Municipality 6 & $\begin{array}{c}0.179 \\
(0.151)\end{array}$ & $\begin{array}{l}-0.0127 \\
(0.0329)\end{array}$ & $\begin{array}{l}-0.277 \\
(0.185)\end{array}$ & $\begin{array}{l}-0.00388 \\
(0.0693)\end{array}$ & $\begin{array}{l}0.00874 \\
(0.0205)\end{array}$ \\
\hline Municipality 7 & $\begin{array}{c}0.184 \\
(0.151)\end{array}$ & $\begin{array}{l}-0.0244 \\
(0.0284)\end{array}$ & $\begin{array}{c}-0.284 \\
(0.185)\end{array}$ & $\begin{array}{l}-0.0213 \\
(0.0672)\end{array}$ & $\begin{array}{c}0.0152 \\
(0.0218)\end{array}$ \\
\hline Municipality 8 & $\begin{array}{c}0.187 \\
(0.151)\end{array}$ & $\begin{array}{l}-0.0536 \\
(0.0393)\end{array}$ & $\begin{array}{c}-0.284 \\
(0.185)\end{array}$ & $\begin{array}{l}-0.180^{*} \\
(0.0795)\end{array}$ & $\begin{array}{c}0.0118 \\
(0.0217)\end{array}$ \\
\hline Municipality 9 & $\begin{array}{c}0.183 \\
(0.151)\end{array}$ & $\begin{array}{c}0.0400 \\
(0.0474)\end{array}$ & $\begin{array}{l}-0.278 \\
(0.185)\end{array}$ & $\begin{array}{l}-0.0697 \\
(0.0879)\end{array}$ & $\begin{array}{c}0.0135 \\
(0.0218)\end{array}$ \\
\hline Municipality 10 & $\begin{array}{c}0.183 \\
(0.151)\end{array}$ & $\begin{array}{l}-0.0212 \\
(0.0374)\end{array}$ & $\begin{array}{l}-0.280 \\
(0.185)\end{array}$ & $\begin{array}{l}-0.00633 \\
(0.0756)\end{array}$ & $\begin{array}{c}0.0140 \\
(0.0218)\end{array}$ \\
\hline Municipality 11 & $\begin{array}{c}0.181 \\
(0.151)\end{array}$ & $\begin{array}{c}-0.106 \\
(0.0640)\end{array}$ & $\begin{array}{c}-0.282 \\
(0.185)\end{array}$ & $\begin{array}{l}-0.0572 \\
(0.0960)\end{array}$ & $\begin{array}{l}0.00599 \\
(0.0220)\end{array}$ \\
\hline Municipality 12 & $\begin{array}{c}0.180 \\
(0.151)\end{array}$ & Omitted & $\begin{array}{l}-0.280 \\
(0.185)\end{array}$ & Omitted & $\begin{array}{c}0.0233 \\
(0.0247)\end{array}$ \\
\hline Municipality 13 & $\begin{array}{c}0.181 \\
(0.151)\end{array}$ & $\begin{array}{l}-0.148 \\
(0.106)\end{array}$ & $\begin{array}{l}-0.283 \\
(0.185)\end{array}$ & $\begin{array}{c}0.215^{* *} \\
(0.0767)\end{array}$ & $\begin{array}{c}0.0135 \\
(0.0217)\end{array}$ \\
\hline Municipality 14 & $\begin{array}{c}0.172 \\
(0.151)\end{array}$ & $\begin{array}{l}-0.00507 \\
(0.0554)\end{array}$ & $\begin{array}{l}-0.270 \\
(0.185)\end{array}$ & $\begin{array}{l}0.0977 \\
(0.118)\end{array}$ & $\begin{array}{c}0.0150 \\
(0.0225)\end{array}$ \\
\hline Municipality 15 & $\begin{array}{c}0.182 \\
(0.151)\end{array}$ & $\begin{array}{l}-0.0662 \\
(0.0398)\end{array}$ & $\begin{array}{l}-0.276 \\
(0.185)\end{array}$ & $\begin{array}{l}-0.0960 \\
(0.0710)\end{array}$ & $\begin{array}{c}0.0102 \\
(0.0219)\end{array}$ \\
\hline Municipality 16 & $\begin{array}{c}0.185 \\
(0.151)\end{array}$ & $\begin{array}{l}-0.0859 \\
(0.0517)\end{array}$ & $\begin{array}{l}-0.281 \\
(0.185)\end{array}$ & $\begin{array}{l}-0.0807 \\
(0.0957)\end{array}$ & $\begin{array}{l}0.00332 \\
(0.0222)\end{array}$ \\
\hline $\begin{array}{l}\text { F statistic for joint } \\
\text { significance }\end{array}$ & 1.34 & 0.84 & 1.06 & 3.21 & 1.33 \\
\hline Prob > F (p-value) & 0.16 & 0.63 & 0.39 & 0.00 & 0.17 \\
\hline Observations & 81,758 & 39,730 & 81,758 & 19,345 & 81,758 \\
\hline
\end{tabular}

Notes: The coefficients and standard error are from regressions on the dependent variable listed at the top of the column controlling for physician fixed effects, quarter-year for each municipality fixed effects, diagnosis fixed effects, and patient age and sex. The sample is visits to clinics prior to the implementation of the separating policy in the township in which the clinic is located for clinics that we not integrated at baseline. The standard errors are clustered at the township level and ${ }^{* * *} \mathrm{p}<0.01,{ }^{* *} \mathrm{p}<0.05$. 